\title{
Long-Term Vibration Monitoring of the Effects of Temperature and Humidity on PC Girders with and without Fly Ash considering ASR Deterioration
}

\author{
Tuan Minh Ha, ${ }^{1}$ Saiji Fukada, ${ }^{2}$ and Kazuyuki Torii $^{2}$ \\ ${ }^{1}$ Graduate School of Natural Science and Technology, Kanazawa University, Kanazawa, Japan \\ ${ }^{2}$ School of Environmental Design, Kanazawa University, Kanazawa, Japan \\ Correspondence should be addressed to Tuan Minh Ha; minhtuan09xdbk@gmail.com
}

Received 26 May 2017; Accepted 27 July 2017; Published 26 September 2017

Academic Editor: Chao Tao

Copyright (C) 2017 Tuan Minh Ha et al. This is an open access article distributed under the Creative Commons Attribution License, which permits unrestricted use, distribution, and reproduction in any medium, provided the original work is properly cited.

Structural responses have been used as inputs in the evaluation procedures of civil structures for years. Apart from the degradation of a structure itself, changes in the environmental conditions affect its characteristics. For adequate maintenance, it is necessary to quantify the environment-induced changes and discriminate them from the effects due to damage. This study investigates the variation in the vibration responses of prestressed concrete (PC) girders, which were deteriorated because of the alkali-silica reaction (ASR), concerning ambient temperature and humidity. Three PC girders were exposed to outdoor weather conditions outside the laboratory, one of which had a selected amount of fly ash in its mixture to mitigate the ASR. The girders were periodically vibration tested for one and a half years. It was found that when the temperature and humidity increased, the frequencies and damping ratios decreased in proportion. No apparent variation in the mode shapes could be identified. A finite element model was proposed for numerical verification, the results of which were in good agreement with the measured changes in the natural frequencies. Moreover, the different dynamic performances of the three specimens indicated that the fly ash significantly affected the vibrations of the PC girders under ASR deterioration.

\section{Introduction}

In the structural health monitoring of concrete bridges, it is important to assess the relationship between the structural performance and the state of damage to conduct maintenance. Hence, the responses of a structure, which are divided into static and dynamic responses, are vital.

Over the years, many studies have been performed on the application of dynamic responses and damage detection [17] in terms of the natural frequencies, mode shapes, modal curvature, and high-order mode shape derivative. A recent study demonstrated that natural frequencies, mode shapes, and damping ratios are invariant in structures [1]. Thus, the health of a structure is correlated to the changes in its modal parameters. The variations in these parameters do not depend on the location of the damage because of their global characteristics. Hence, the deterioration can be estimated using sensors mounted at any position on a structure. In particular, the changes in the natural frequency have been thoroughly investigated as identifiers of stiffness reduction [2]. In addition, the changes in the uncertain frequency, mode shape data [3], incomplete mode shape [4], mode shape curvatures [5], and flexibility matrix [6] were used to localize the damage. The variation in the elemental modal strain energy was applied to improve damage quantification [7]. Hence, most of the studies focused on using structural responses to identify the properties of damage (occurrence, location, and severity), whereas only a few studies discussed the effects of environmental conditions on the variations in the structural characteristics (dynamic and static responses). If the effects of these uncertainties on the structural properties are greater than or comparable to the effects of structural damage, the structural damage cannot be reliably identified [8]. Therefore, studying the environmental effects on the structural properties is important to effectively apply the monitoring methods to civil engineering structures. 
During the past few decades, the correlations between the vibrational characteristics and temperature changes have attracted considerable interest in technical literature and have been investigated using different approaches such as numerical analysis via finite element (FE) methods $[9,10]$, laboratory tests $[8,11]$, and monitoring approaches in civil structures $[1,12,13]$.

Theoretical Derivation Method. Macdonald and Daniell [9] performed modal analyses under two different temperature conditions using an FE model of a cable-stayed bridge with a main span of $456 \mathrm{~m}$. A uniform change of $5^{\circ} \mathrm{C}$ in the entire structure was considered under the first condition, whereas a temperature gradient of $+10^{\circ} \mathrm{C}$ was assumed between the top of the deck and the rest of the structure under the second condition. With regard to the FE model, beam elements and four shell elements were used to model the longitudinal girders and reinforced concrete (RC) slab of the deck, respectively. The results showed that the natural frequencies of approximately one-third of the modes shifted by up to $\pm 0.2 \%$ under both cases, whereas no clear variation was observed in the others. Xu and $\mathrm{Wu}$ [10] investigated the effects of uniform and nonuniform temperature fluctuations on the frequency and changes in the mode shape curvature of a cable-stayed concrete box girder bridge using threedimensional FE analysis. Their results proved that the variation behaviors in the frequency and mode shape curvature under the effect of a nonuniform change in the temperature were the same as that under the effect of a uniform change in the temperature. Moreover, the maximum variation ratio of the frequency was $\sim 2 \%$ when the uniform temperature gradient increased by $\sim 60^{\circ} \mathrm{C}$. The effect of the temperature on the frequencies was significant in the vertical bending mode.

Laboratory Test Approach. With regard to the laboratory test approach, previous studies provided rational conclusions about the variations in the vibrational responses under different environmental conditions. Xia et al. [8] performed periodic vibration tests on a reinforced concrete slab for approximately two years. It was perceived that the frequencies of the first four modes had a strong negative correlation with the temperature, whereas the increases in the damping ratios with the increase in the temperature were insignificant, and no clear correlation of the mode shapes could be observed with respect to the temperature difference. In particular, the natural frequencies of the three bending modes decreased by $0.13-0.23 \%$ when the temperature increased by $1^{\circ} \mathrm{C}$. However, the sensitivities of the torsional mode and bending rigidity to the temperature were different. Kim et al. [11] observed similar outcomes. They reported that the bending modes were more sensitive than the torsional modes. With regard to the lower modes, the effect of the temperature on the change in the natural frequency is relatively greater. Moreover, two levels of damage were inflicted on a girder near the center of the structure: the bottom flange was cut halfway in from the outside, and the bottom flange was cut completely in from either side. Consequently, the changes in the vibration properties due to the damage were largely similar to those due to the temperature fluctuations.
Trend Analysis Approach. So far, only a few studies have monitored the changes in the structural responses of fullscale bridges considering environmental effects $[1,12,13]$. Cornwell et al. reported that the first three natural frequencies of the Alamosa Canyon Bridge varied by approximately 4.7, 6.6 , and $5.0 \%$ during a $24 \mathrm{~h}$ period as the temperature of the bridge deck changed by approximately $22^{\circ} \mathrm{C}$ [12]. Later, with the support of the European SIMCES-project, Peeters and De Roeck [13] monitored the Z24 Bridge in Switzerland for one year. In particular, black-box models were developed from the healthy-bridge data to describe the variations in the eigenfrequencies due to the changing environmental conditions. The monitored data were then analyzed with the reference data, and the damage was recognized when an eigenfrequency varied beyond certain confidence intervals from the proposed model. In addition, the results of the monitored data show that the first four vibration frequencies varied by $14-18 \%$ during the ten months of analysis. The frequencies of all the modes analyzed, except the second mode, decreased with the increase in the temperature. In another study worth mentioning, Huth et al. [1] identified the damage using modal data for the Romeo Bridge in Switzerland. The results suggested that a criterion for the damage detection based on the mode shape area might perform better than that based on the variations in the natural frequencies. Furthermore, the obtained monitoring data showed that the effects of the environmental parameters were considerable, particularly that of the change in the temperature, on the natural frequencies.

Among the different laboratory approaches employed for evaluating the changes in the vibration properties with respect to the environmental conditions, simultaneous effects of structural degradation over the monitoring period on the observation data have not been explicitly reported. Ha et al. [14] showed that the natural frequency of the first bending mode decreased gradually until the destruction of the objective girder. Before the yielding load, the decreasing rate was estimated to be within $\sim 6 \%$. However, this rate clearly increased to approximately $31 \%$ when the natural frequencies measured before the test and at the final loading state were compared. Thus, there was a decrease in the natural frequency of the first bending mode in accordance with the increase in the structural degradation, that is, cracks due to loading. With the aim of contributing to efficient structural health monitoring approaches, this study investigates the effects of environmental conditions on the vibrational properties of prestressed concrete (PC) girders, which were affected by varying degrees of deteriorations induced by an alkali-silica reaction (ASR). Because the environmental conditions induce complicated uncertainties in the structural responses, this study only examines the variations in the frequencies, mode shapes, and damping with respect to the changes in the temperature and humidity. Three full-size PC girders, which were periodically vibration tested for one and a half years to obtain their dynamic properties, were exposed to outdoor weather conditions outside a laboratory. Two of the PC girders were affected by the ASR whereas the third girder was kept at an inactive state by suppressing the acceleration of the ASR using the fly ash. First, the vibration characteristics 

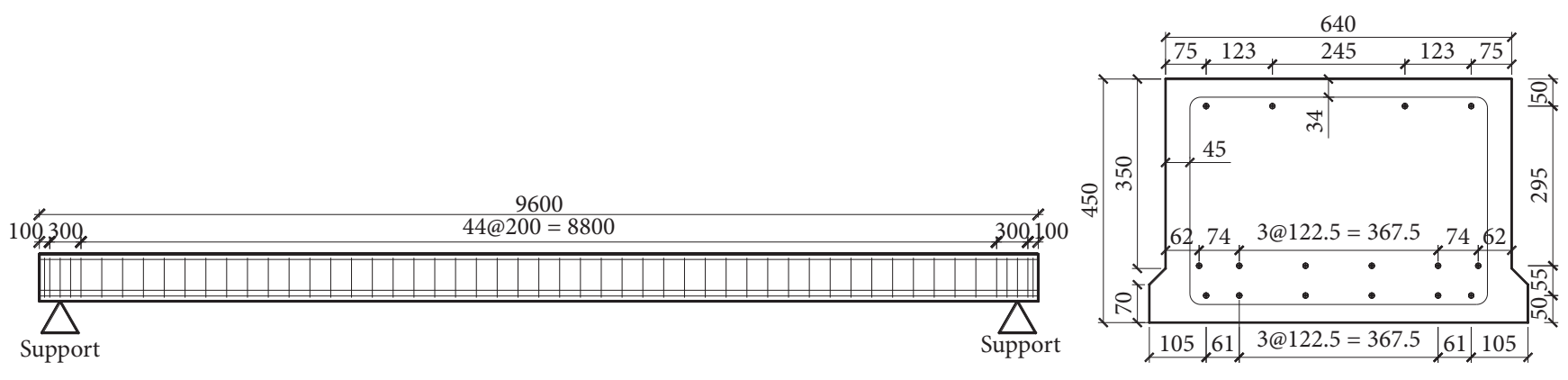

FIGURE 1: Diagram of PC girders (unit: $\mathrm{mm}$ ).

of the girders, such as the vibration frequencies, mode shapes, and damping ratios, were extracted from the measurement data along with the ambient temperature and humidity during each test. The frequencies and damping ratios were then analyzed using linear regression models with respect to the variations in the temperature and humidity. The temperature and humidity increased in proportion with the decreases in the frequency and damping ratio, whereas no clear correlation of the mode shapes with the changes in the temperature and humidity could be observed. In addition, different dynamic behaviors were well observed in the three PC girders over the monitoring period. In particular, along with fewer ASR-induced cracks, the girder with fly ash exhibited higher vibration frequencies and lower damping ratios compared to the girders without the fly ash. Thus, the fly ash significantly affected the vibration properties of the PC girders subjected to the ASR-induced deteriorations. Because Young's modulus of concrete is temperature dependent, the changes in the natural frequencies of the PC girders due to the ambient temperature can be simulated using a finite element (FE) model [15]. Another objective of this study includes performing validation tests of the numerical analyses against the results of the measurement by assuming Young's modulus of concrete as a function of the temperature. The results showed that the validation model provided reasonable illustrations for the changes in the natural frequency of the vibration modes due to the changes in the ambient temperature.

\section{Description of the PC Girders}

2.1. Shapes and Exposure Conditions. The PC girders selected for this study were in accordance with the specifications of a full-size JIS A5373-AS09 girder. The side and cross-sectional views of the girders were the same, as shown in Figure 1. The length and height of each girder were 9600 and $450 \mathrm{~mm}$, respectively. The upper and lower edge widths of the cross section of each girder were 640 and $700 \mathrm{~mm}$, respectively. Each girder contained sixteen strands (SWPR7BL1S $12.7 \mathrm{~mm}$ ) arranged longitudinally in three layers. In particular, four strands were placed in the first layer in the compression area whereas the other two layers comprising six strands each were arranged in the tension area. The girders, which were obtained using a pretensioning method, had the same profiles and dimensions as the strands and stirrups. After $14 \mathrm{~h}$ of steam curing at $50^{\circ} \mathrm{C}$, the tendons were released from

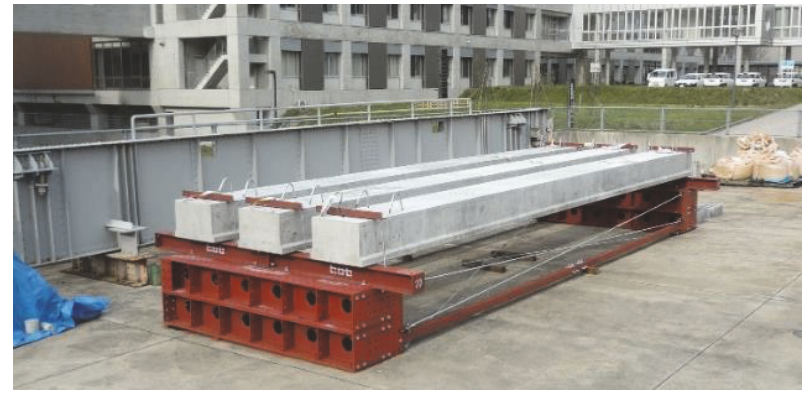

Figure 2: PC girders constructed for this study.

the external frames, and subsequently, the PC girders were continuously moistened indoor for approximately one week. Following the initial curing, they were placed in a sunny area of the Kakuma campus to expose them to the outdoor environment for one and a half years (see Figure 2).

2.2. Mixture. Three specimens were cast using the mixtures listed in Table 1. In this study, high-strength Portland cement was used for all the girders. One of them, namely, girder No. 3 , was mixed with fly ash to mitigate the expansion of the concrete due to the ASR. The replacement rate of the fly ash to binder was set to $15 \%$ considering the quality and workability of the classified ash from a previous research result [16], wherein the effectiveness of the fly ash in reducing the ASRinduced damage was confirmed. Moreover, to promote the expansion of the concrete via the ASR, $18.87 \mathrm{~kg} / \mathrm{m}^{3} \mathrm{NaCl}$ in an equivalent amount of $10 \mathrm{~kg} / \mathrm{m}^{3} \mathrm{Na}_{2} \mathrm{O}$ was added to the mixture of girder No. 1, whereas No. 2 and No. 3 were mixed with $25.5 \mathrm{~kg} / \mathrm{m}^{3} \mathrm{NaCl}$ in an equivalent amount of $13 \mathrm{~kg} / \mathrm{m}^{3}$ $\mathrm{Na}_{2} \mathrm{O}$.

2.3. Deterioration Situations of PC Girders. Figures 3(a)-3(c) show the crack patterns of the three girders after one and a half years of outdoor exposure. The black lines indicate the crack widths in the range of $0.3-0.8 \mathrm{~mm}$ whereas the crack widths over $0.8 \mathrm{~mm}$ are indicated using red lines. On the side and top surfaces of girders No. 1 and No. 2, many cracks formed along the girder axis, whereas a few cracks could be observed on the lower surfaces. Cracks partially formed near the ends and on the side surfaces of girder No. 3. Because the 
TABLE 1: Mixture properties.

\begin{tabular}{|c|c|c|c|c|c|c|c|c|}
\hline \multirow{3}{*}{ Name } & \multirow{3}{*}{$\begin{array}{l}\text { Water-binder } \\
\text { ratio W/B (\%) }\end{array}$} & \multirow{3}{*}{$\begin{array}{c}\text { Fine aggregate } \\
\text { percentage s/a }(\%)\end{array}$} & \multicolumn{6}{|c|}{ Unit $\left(\mathrm{Kg} / \mathrm{m}^{3}\right)$} \\
\hline & & & \multirow{2}{*}{ Water W } & \multicolumn{2}{|c|}{ Binder B } & \multirow{2}{*}{ Sand S } & \multirow{2}{*}{ Gravel G } & \multirow{2}{*}{$\mathrm{NaCl}$} \\
\hline & & & & Cement C & Fly ash FA & & & \\
\hline No. 1 & 38.7 & 46.3 & 150 & 388 & - & 822 & 955 & 18.87 \\
\hline No. 2 & 38.7 & 46.3 & 150 & 388 & - & 822 & 955 & 25.5 \\
\hline No. 3 & 34.8 & 44.6 & 150 & 366 & 65 & 770 & 955 & 25.5 \\
\hline
\end{tabular}

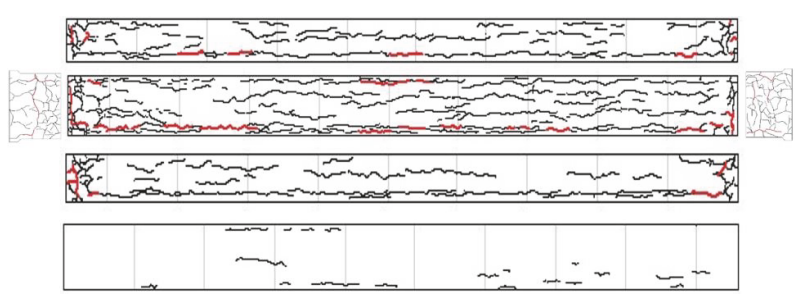

(a) Girder No. 1

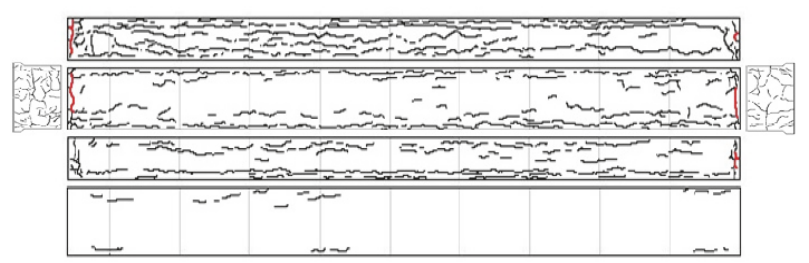

(b) Girder No. 2

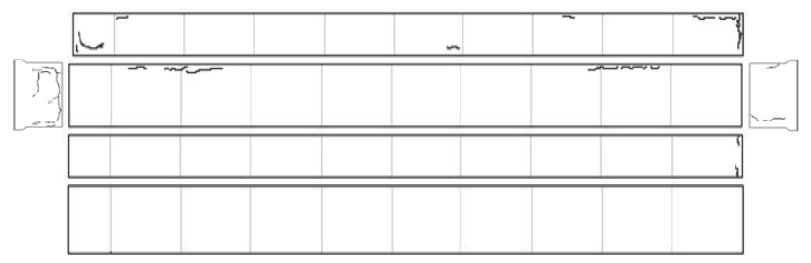

(c) Girder No. 3

Figure 3: ((a)-(c)) Crack patterns of the girders (from top to bottom: north surface, top surface and both surfaces near both ends, south surface, and bottom surfaces).

number of cracks was considerably small, the expansion of the ASR was effectively suppressed owing to the fly ash.

2.4. Experimental Procedure. To obtain free damped vibrations of the three PC girders, 14 accelerometers were placed on the girder with a constant interval of $1.15 \mathrm{~m}$, as shown in Figure 4. During each test, the impact excitations were applied alternately via a person jumping vertically from a chair (see Figure 5) at four locations depicted as " $x$ " in Figure 4. At every impact location, the measurement was conducted two times, with 10000 data points collected at a sampling period of $5 e-3 \mathrm{~s}$ each time. The vibration parameters of the PC girders were extracted from the measured data using the eigensystem realization algorithm (ERA) [17]. An FE model was then employed to conduct a structural eigenvalue analysis and estimate the natural frequency of the PC girder to compare the results with the measurements. Moreover, the ambient temperature and humidity were recorded simultaneously during the test using a thermometer. To track the variation in the vibrational parameters due to the environmental effects and ASR, eight tests were performed from May 2015 to September 2016 with 192 valid sets of vibration data.

\section{Environmental Effect of PC Girders on Vibrational Parameters}

In this study, the first three modal properties were extracted from the measured data using the ERA [17]. Figures 6(a)-6(c) show their typical shapes for modes 1,2 , and 3 , respectively. In particular, modes 1 and 2 are the first and second bending modes, respectively, whereas mode 3 is the first mode of the torsional vibration. To evaluate the effects of the ambient temperature and humidity on the changes in the dynamic responses, linear regression analyses were performed on all modal properties of the girders. The results and discussions are presented in the following sections.

\subsection{Changes in Natural Frequencies}

3.1.1. Evaluation of Ambient Temperature Effects. Figures $7(\mathrm{a})-7(\mathrm{c}), 8(\mathrm{a})-8(\mathrm{c})$, and $9(\mathrm{a})-9(\mathrm{c})$ show the negative correlations between the three first modal frequencies of the girders and the ambient temperature (specified in degree Celsius throughout this study), which were measured during the monitoring period. These figures show that the amplitude of the vibrational frequency decreased with respect to the increased ambient temperature.

To obtain more information about the linear relationships of the natural frequencies with respect to the temperature, a linear regression model was proposed. The corresponding empirical equation of the natural frequency $(f)$ as a function of the temperature $(T)$ is as follows.

$$
f=\alpha_{0}+\beta_{t} T+\varepsilon_{f}
$$

where $f$ is the natural frequency, $\alpha_{0}$ and $\beta_{t}$ are the regression coefficients named the intercept and the gradient, respectively, and $\varepsilon_{f}$ is the regression error. The measured ambient temperature was used as an explanatory variable. In this study, R was employed for statistical computing [18]. With regard to the results of the statistical analyses, Tables 2-4 list the estimated regression coefficients for girders No. 1, No. 2, and No. 3 , respectively.

From Tables 2, 3, and 4, the coefficients of determination $R^{2}$ for the three modes of girder No. 3 were estimated at 
TABLE 2: Coefficients of linear regression model (frequency $\sim$ temperature) of girder No. 1.

\begin{tabular}{lcccccc}
\hline Mode & Intercept $\alpha_{0}$ & Gradient $\beta_{t}$ & Std. Error $\sigma_{\varepsilon_{f}}$ & $\sigma_{\varepsilon_{f}} / \alpha_{0}(\%)$ & $\beta_{t} / \alpha_{0}(\%)$ & Coefficient of determination $R^{2}$ \\
\hline 1 & 9.3641 & -0.0132 & 0.0493 & 0.5269 & -0.1411 & 0.4111 \\
2 & 36.9501 & -0.0802 & 0.1775 & 0.4803 & -0.2171 & 0.7218 \\
3 & 31.4923 & -0.1659 & 1.0982 & 3.4872 & -0.5269 & 0.3975 \\
\hline
\end{tabular}

TABLE 3: Coefficients of linear regression model (frequency $\sim$ temperature) of girder No. 2 .

\begin{tabular}{lcccccc}
\hline Mode & Intercept $\alpha_{0}$ & Gradient $\beta_{t}$ & Std. Error $\sigma_{\varepsilon_{f}}$ & $\sigma_{\varepsilon_{f}} / \alpha_{0}(\%)$ & $\beta_{t} / \alpha_{0}(\%)$ & Coefficient of determination $R^{2}$ \\
\hline 1 & 9.9069 & -0.0147 & 0.0581 & 0.5864 & -0.1489 & 0.3821 \\
2 & 35.5043 & -0.0540 & 0.6280 & 1.7687 & -0.1520 & 0.1444 \\
3 & 32.7528 & -0.2204 & 2.2470 & 6.8604 & -0.6729 & 0.2280 \\
\hline
\end{tabular}

TABLE 4: Coefficients of linear regression model (frequency $\sim$ temperature) of girder No. 3.

\begin{tabular}{lcccccc}
\hline Mode & Intercept $\alpha_{0}$ & Gradient $\beta_{t}$ & Std. Error $\sigma_{\varepsilon_{f}}$ & $\sigma_{\varepsilon_{f}} / \alpha_{0}(\%)$ & $\beta_{t} / \alpha_{0}(\%)$ & Coefficient of determination $R^{2}$ \\
\hline 1 & 10.2691 & -0.0177 & 0.0286 & 0.2785 & -0.1725 & 0.7932 \\
2 & 37.2520 & -0.0850 & 0.1425 & 0.3825 & -0.2281 & 0.8567 \\
3 & 33.1032 & -0.3239 & 0.8411 & 2.5408 & -0.9785 & 0.7911 \\
\hline
\end{tabular}

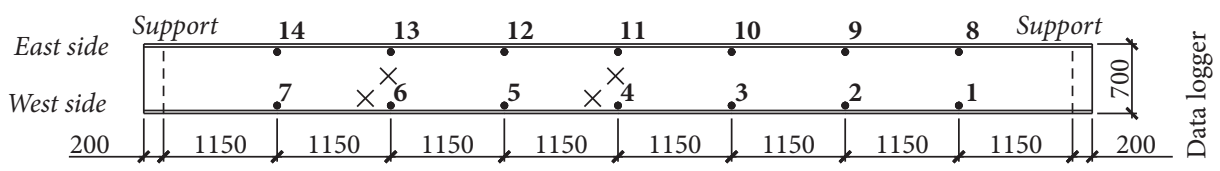

$\times$ Impact point

- Accelerometers

FIGURE 4: Sensor layout on the PC girder.

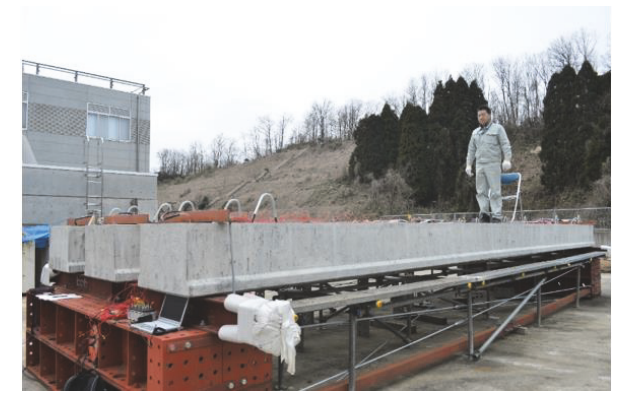

Figure 5: Impact test and sensor layout on the PC girder.

approximately 0.8 . Moreover, in comparison to the other two girders, this coefficient was obtained at much lower values. Therefore, approximately $80 \%$ of the vibration frequency variances of girder No. 3 could be accounted for with respect to the ambient temperature. In particular, a change of $85.67 \%$ in the frequency of the second bending mode could be due to the change in temperature. However, changes of $\sim 41.11$, 72.18 , and $39.75 \%$ in modes 1,2 , and 3 , respectively, of girder No. 1 were predictable, whereas the variance in the vibration frequency of girder No. 2 was the least explainable among the three. The correlation levels were relatively moderate for girders No. 1 and No. 2 but fairly strong for girder No.
3. Figures 7, 8, and 9 show the fitted regression lines and corresponding equations. The standard deviations of the error (Std. Error $\sigma_{\varepsilon_{f}}$ ) were obtained as 0.0493, 0.1775, and 1.0982 for modes 1, 2, and 3 of girder No. 1, respectively, as observed in Table 2. Dividing $\sigma_{\varepsilon_{f}}$ by the intercept $\left(\alpha_{0}\right)$ yields $0.5269,0.4803$, and $3.4872 \%$, which indicate the uncertainties due to other factors such as measurement noise, analysis error or effects of ambient humidity [8], and ASR-induced deterioration. Because the error ratio of the torsional mode was higher than that of the bending modes, it is found that the bending modes could be estimated more accurately than the torsional mode. Similar outcomes were also observed with respect to the vibration modes of the other two girders. To quantify the effect of the measured temperature on the frequency change, the gradients $\left(\beta_{t}\right)$ were normalized to the intercepts $\left(\alpha_{0}\right)$. The results show that, for all girders, the torsional frequencies decreased by $0.52-0.97 \%$ as the temperature increased by $1^{\circ} \mathrm{C}$, whereas the measured frequencies of the bending modes decreased by approximately $0.1-0.2 \%$.

3.1.2. Evaluation of Ambient Humidity Effects. In this study, the effect of humidity variation on the change in the vibration frequency of the PC girders was analyzed. Figures $10(a)-10(c), 11(a)-11(c)$, and 12(a)-12(c) show the correlations of all the identified data of the first three modal frequencies 


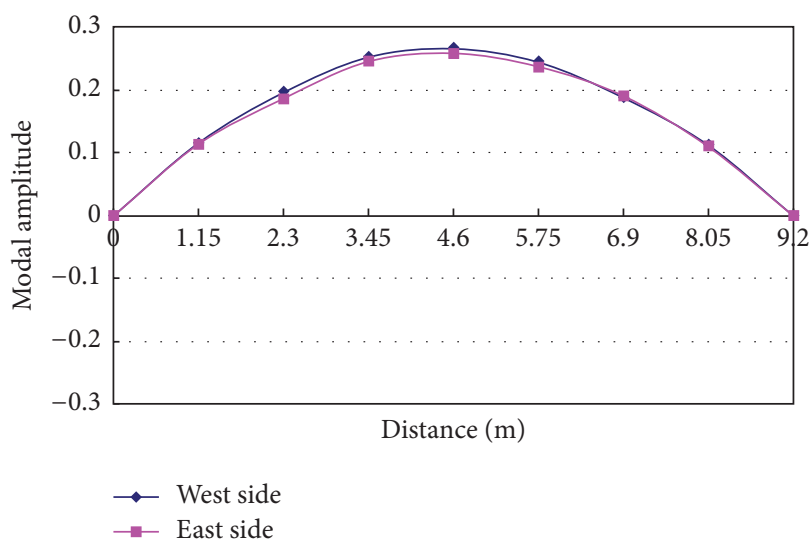

(a) The 1st bending mode (mode 1), $f=9.593 \mathrm{~Hz}$

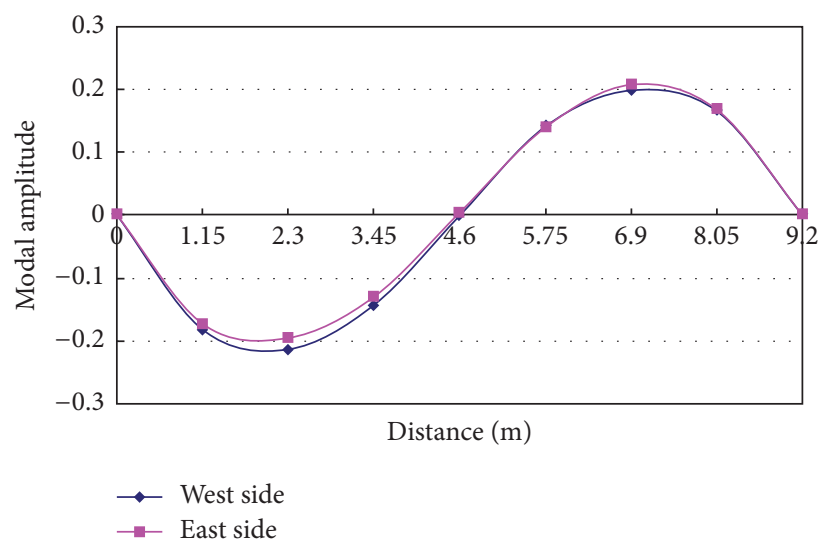

(b) The 2nd bending mode (mode 2), $f=34.506 \mathrm{~Hz}$

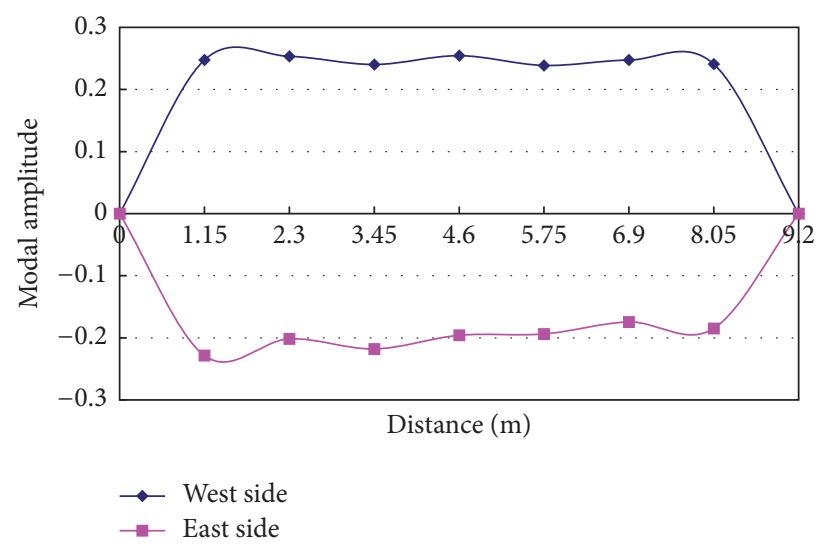

(c) The 1st mode of torsional vibration (mode 3), $f=22.360 \mathrm{~Hz}$

Figure 6: ((a)-(c)) Measured frequencies of girder No. 3 in May 2015.

with respect to the ambient humidity (specified in percent throughout this study). These figures demonstrate that all the three frequencies decreased with the increase in the humidity. Moreover, the relationship between the measured frequencies and the humidity was relatively linear.

The linear regression analyses were performed to investigate the goodness of fit of the linear relationship using $\mathrm{R}$ [18]. A linear regression model was proposed. The corresponding empirical equation of the natural frequency $(f)$ as a function of the humidity $(H)$ is assumed as follows.

$$
f=\alpha_{0}+\beta_{h} H+\varepsilon_{f}
$$

where $f$ is the natural frequency, $\alpha_{0}$ and $\beta_{h}$ are the regression coefficients named the intercept and the gradient, respectively, and $\varepsilon_{f}$ is the regression error. With regard to the results of the statistical analyses, Tables 5-7 list the estimated regression coefficients for girders No. 1, No. 2, and No. 3, respectively.

The coefficients of determination $R^{2}$ for the three frequencies of girder No. 3 were $0.2613,0.5898$, and 0.3931 , respectively, and the corresponding correlation coefficients $R$ were $0.5112,0.768$, and 0.627 , respectively, implying that there was a moderate correlation between the two variables. For girders No. 1 and No. 2, the $R^{2}$ factors for the two bending modes were estimated as 0.8732 and 0.8614 and 0.6908 and 0.4145 , respectively, which yielded high values of the correlation coefficient $R$, that is, 0.9345 and 0.9281 for girder No. 1 and 0.8314 and 0.644 for girder No. 2. Thus, there was a good correlation between the frequencies of the bending modes with respect to the ambient humidity with regard to the two girders. In contrast, with regard to the torsional modes, the linear relationships between the two variables were weak because of the low coefficients of determination $R^{2}$. The result of the regression analysis shows that the ambient humidity affected the frequencies of the bending modes of the girders No. 1 and No. 2 more significantly than that of girder No. 3 . This is because the concrete absorbs more water in higher humidity environment and increases the mass; moreover, the natural frequencies decrease with the increase in the humidity [8]. Because of the ASR-induced cracks, water could be absorbed and dispersed easily in the girders No. 1 and No. 2. Thus, these two girders were more sensitive to the ambient humidity than girder No. 3 containing the fly ash. For a detailed comparison between the three girders, the gradients $\left(\beta_{t}\right)$ were normalized to the intercepts $\left(\alpha_{0}\right)$. It was found that the frequencies of the two bending modes of girder No. 3 varied by $\sim 0.052 \%$ and $~$ $0.097 \%$ when the humidity changed by $1 \%$. With regard to the frequencies of girders No. 1 and No. 2, the rates 
TABle 5: Coefficients of linear regression model (frequency humidity) of girder No. 1.

\begin{tabular}{lcccccc}
\hline Mode & Intercept $\alpha_{0}$ & Gradient $\beta_{t}$ & Std. Error $\sigma_{\varepsilon_{f}}$ & $\sigma_{\varepsilon_{f}} / \alpha_{0}(\%)$ & $\beta_{t} / \alpha_{0}(\%)$ & Coefficient of determination $R^{2}$ \\
\hline 1 & 9.4902 & -0.0084 & 0.0251 & 0.2643 & -0.0885 & 0.8732 \\
2 & 37.1382 & -0.0393 & 0.1450 & 0.3904 & -0.1058 & 0.8614 \\
3 & 28.6544 & -0.0227 & 1.2469 & 4.3514 & -0.0792 & 0.0624 \\
\hline
\end{tabular}

TABLE 6: Coefficients of linear regression model (frequency humidity) of girder No. 2.

\begin{tabular}{lcccccc}
\hline Mode & Intercept $\alpha_{0}$ & Gradient $\beta_{t}$ & Std. Error $\sigma_{\varepsilon_{f}}$ & $\sigma_{\varepsilon_{f}} / \alpha_{0}(\%)$ & $\beta_{t} / \alpha_{0}(\%)$ & Coefficient of determination $R^{2}$ \\
\hline 1 & 10.0751 & -0.0095 & 0.0504 & 0.5005 & -0.0940 & 0.6908 \\
2 & 36.7092 & -0.0462 & 0.6605 & 1.7993 & -0.1260 & 0.4145 \\
3 & 31.5830 & -0.0665 & 3.0309 & 9.5965 & -0.2107 & 0.0867 \\
\hline
\end{tabular}

TABLE 7: Coefficients of linear regression model (frequency humidity) of girder No. 3.

\begin{tabular}{lcccccc}
\hline Mode & Intercept $\alpha_{0}$ & Gradient $\beta_{t}$ & Std. Error $\sigma_{\varepsilon_{f}}$ & $\sigma_{\varepsilon_{f}} / \alpha_{0}(\%)$ & $\beta_{t} / \alpha_{0}(\%)$ & Coefficient of determination $R^{2}$ \\
\hline 1 & 10.1603 & -0.0053 & 0.0735 & 0.7236 & -0.0524 & 0.2613 \\
2 & 37.3333 & -0.0364 & 0.3276 & 0.8774 & -0.0974 & 0.5898 \\
3 & 32.8495 & -0.1263 & 2.0293 & 6.1777 & -0.3845 & 0.3931 \\
\hline
\end{tabular}

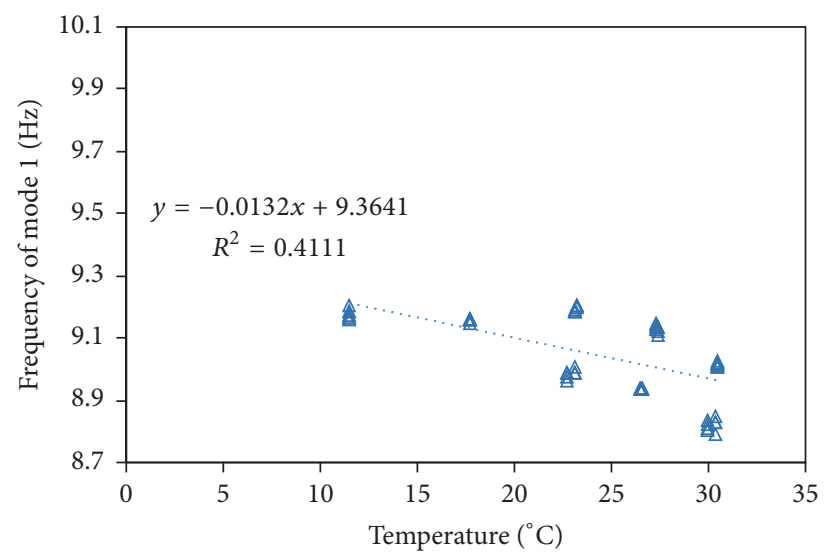

(a) Girder No. 1

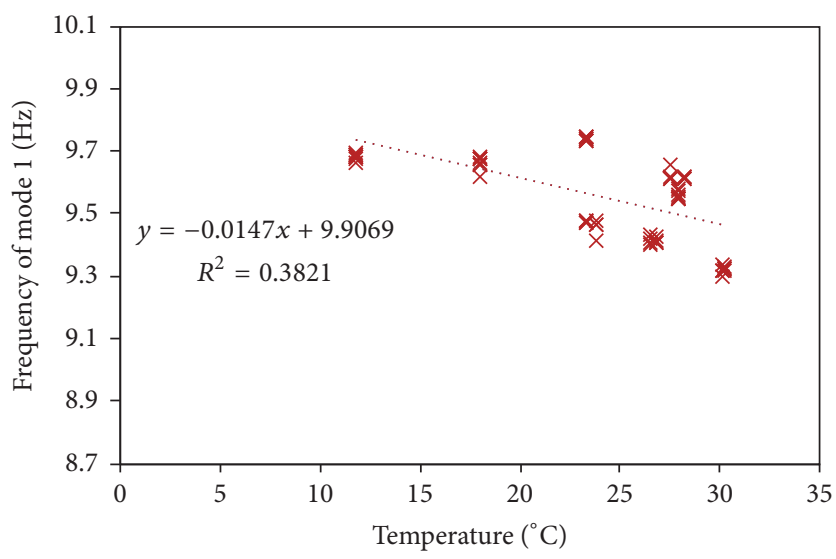

(b) Girder No. 2

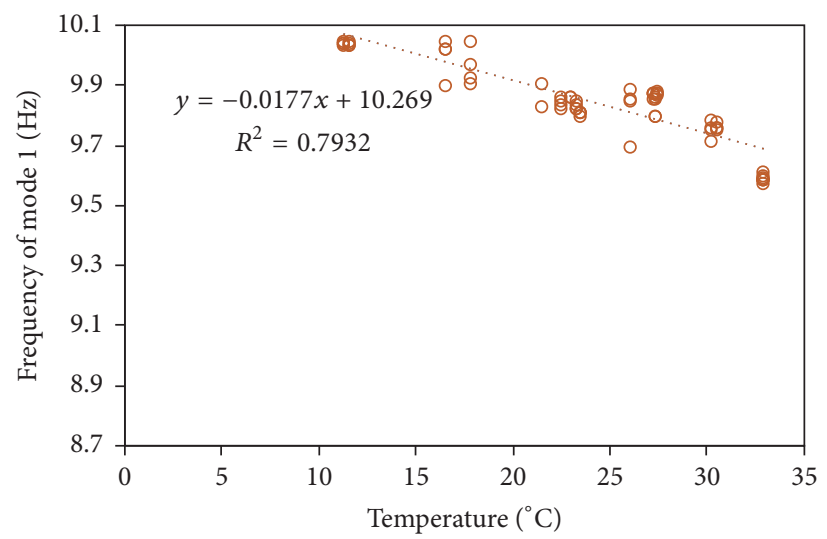

(c) Girder No. 3

FiguRE 7: ((a)-(c)) Relation of frequencies of mode 1 to temperature. 


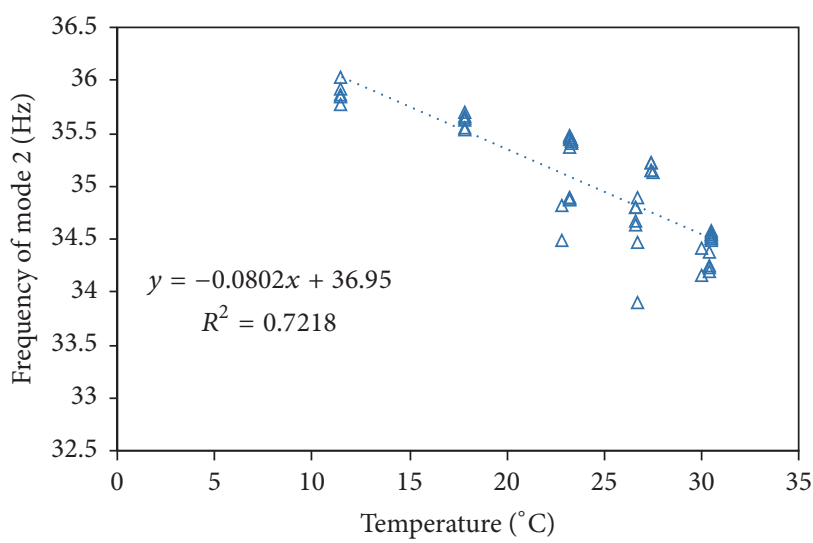

(a) Girder No. 1

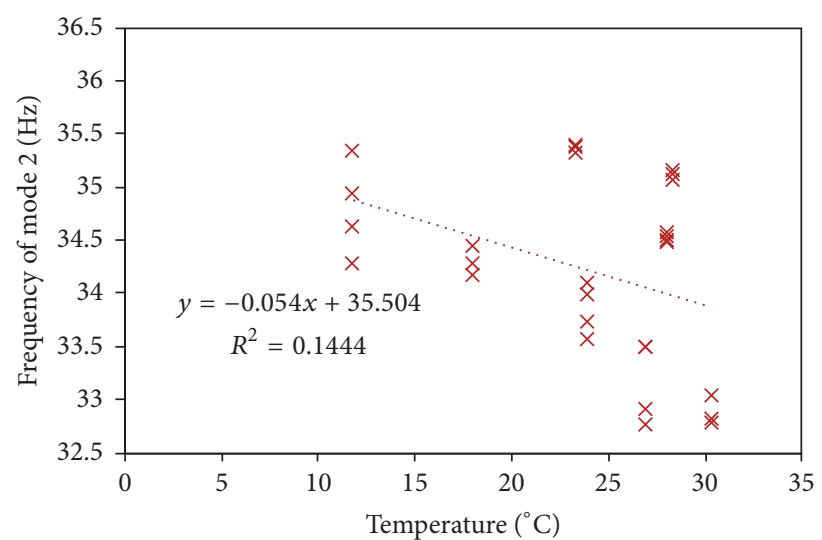

(b) Girder No. 2

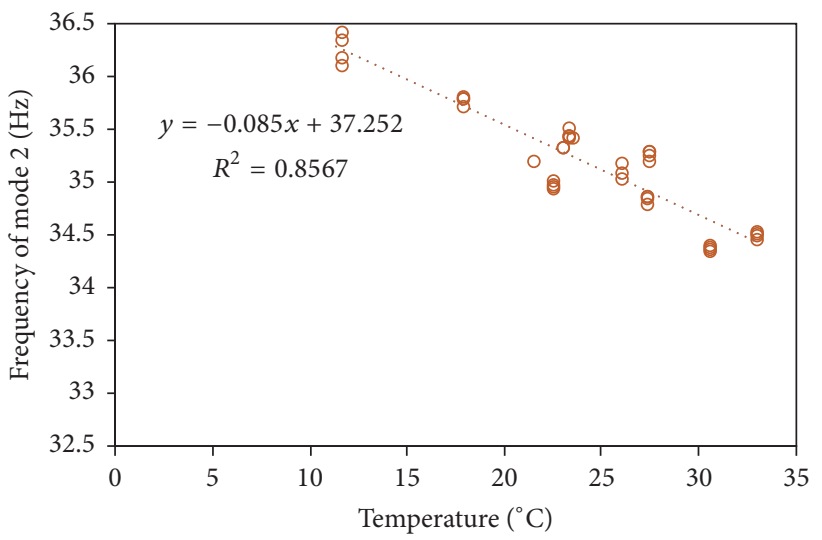

(c) Girder No. 3

Figure 8: ((a)-(c)) Relation of frequencies of mode 2 to temperature.

were calculated at higher values, which were $0.088-0.106 \%$ and $0.094-0.126 \%$, respectively. For the torsional mode, the results differ significantly with the changes in the bending modes. Figures 10, 11, and 12 show the fitted regression lines and corresponding equations.

\subsubsection{Combined Effect of Ambient Temperature and Humidity.} As another form of the linear regression analysis, multiple linear regression was employed to explain the combined effect of the ambient temperature and humidity (independent variables) on the natural frequency (dependent variable). Assuming the humidity as the second variable, the empirical equation of the frequency $(f)$ as a function of the temperature $(T)$ and humidity $(H)$ is given as follows.

$$
f=\alpha_{0}+\beta_{t} T+\beta_{h} H+\varepsilon_{f},
$$

where $f$ is the natural frequency, $\alpha_{0}, \beta_{t}$, and $\beta_{h}$ are the intercept and the gradients of the temperature and humidity, respectively, and $\varepsilon_{f}$ is the regression error. Tables 8-10 list the outcomes for girders No. 1, No. 2, and No. 3, respectively. The results of the $R^{2}$ statistics were estimated at 0.8815 , 0.8725 , and 0.8618 for the three vibration modes of girder No. 3, and the corresponding correlation coefficients $R$ were obtained, respectively, as $0.9389,0.9341$, and 0.9283 , which are significantly higher than the previous results wherein the humidity and temperature were considered separately. The strong correlations between the three variables demonstrate that the ambient humidity and temperature significantly affected the changes in the frequencies of the vibration modes of girder No. 3. In addition, the regression analyses for girders No. 1 and No. 2 yielded similar results because the coefficients of determination were high. The results of the uncertainty evaluation show that the percentage ratios between $\sigma_{\varepsilon_{f}}$ and $\alpha_{0}$ were largely lower than the previous errors. However, the uncertainties in the torsional mode of the three girders were obtained, respectively, as $\sim 2.98, \sim 6.47$, and $\sim 2.95 \%$, which were clearly higher than that of the two bending modes. The fluctuations in estimating the torsional properties are high because the torsional mode is not only affected by the environmental conditions and errors in the measurements and analyses but also governed by the shear rigidity of the structure, which differs from the bending rigidity in terms of the sensitivity to the temperature and humidity [8].

The selected regression models were only suitable for a temperature range of $11.45-33^{\circ} \mathrm{C}$ and a humidity range of $28-73 \%$ as presented in this study. Moser and Moaveni [19] showed, that for a two-span continuous steel frame bridge, the relationships between the natural frequencies of six identified modes and the measured temperature were nonlinear when the temperature ranged from $-14^{\circ} \mathrm{C}$ to $39^{\circ} \mathrm{C}$. 
TABLE 8: Coefficients of linear regression model (frequency $\sim$ temperature + humidity) of girder No. 1 .

\begin{tabular}{lccccc}
\hline Mode & Intercept $\alpha_{0}$ & Std. Error $\sigma_{\varepsilon_{f}}$ & $\sigma_{\varepsilon_{f}} / \alpha_{0}(\%)$ & Coefficient of determination $R^{2}$ & Correlation coefficient $R$ \\
\hline 1 & 9.4809 & 0.0235 & 0.2483 & 0.8923 & 0.9446 \\
2 & 37.2076 & 0.1291 & 0.3470 & 0.8954 & 0.9463 \\
3 & 31.6610 & 0.9425 & 2.9768 & 0.6576 & 0.8109 \\
\hline
\end{tabular}

TABLE 9: Coefficients of linear regression model (frequency $\sim$ temperature + humidity) of girder No. 2 .

\begin{tabular}{lccccc}
\hline Mode & Intercept $\alpha_{0}$ & Std. Error $\sigma_{\varepsilon_{f}}$ & $\sigma_{\varepsilon_{f}} / \alpha_{0}(\%)$ & Coefficient of determination $R^{2}$ & Correlation coefficient $R$ \\
\hline 1 & 10.1880 & 0.0514 & 0.5046 & 0.7691 & 0.8770 \\
2 & 38.7192 & 0.4317 & 1.1150 & 0.8454 & 0.9195 \\
3 & 25.9808 & 1.6800 & 6.4663 & 0.7848 & 0.8859 \\
\hline
\end{tabular}

TABLE 10: Coefficients of linear regression model (frequency $\sim$ temperature + humidity) of girder No. 3 .

\begin{tabular}{lccccc}
\hline Mode & Intercept $\alpha_{0}$ & Std. Error $\sigma_{\varepsilon_{f}}$ & $\sigma_{\varepsilon_{f}} / \alpha_{0}(\%)$ & Coefficient of determination $R^{2}$ & Correlation coefficient $R$ \\
\hline 1 & 10.1673 & 0.0297 & 0.2923 & 0.8815 & 0.9389 \\
2 & 37.3092 & 0.1855 & 0.4973 & 0.8725 & 0.9341 \\
3 & 33.8330 & 0.9980 & 2.9499 & 0.8618 & 0.9283 \\
\hline
\end{tabular}

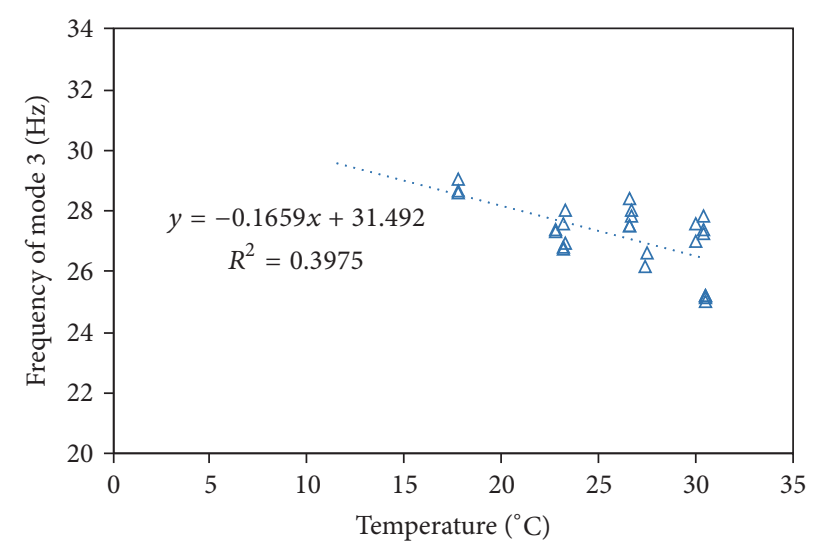

(a) Girder No. 1

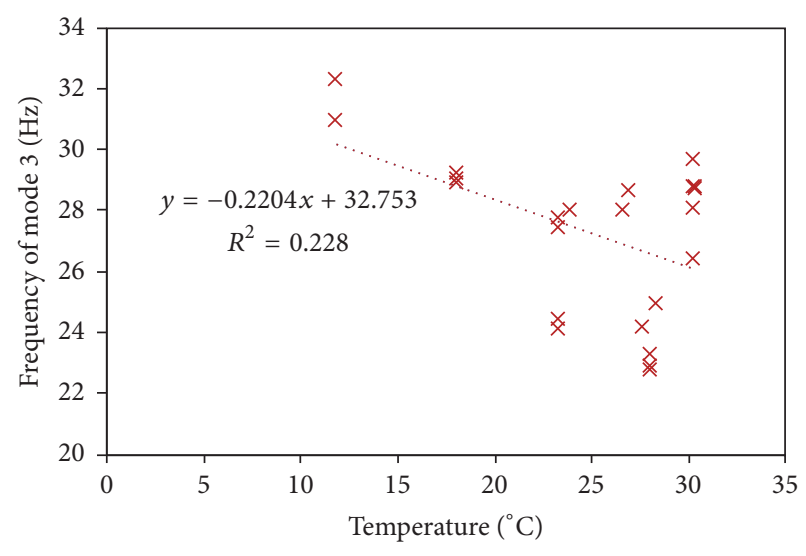

(b) Girder No. 2

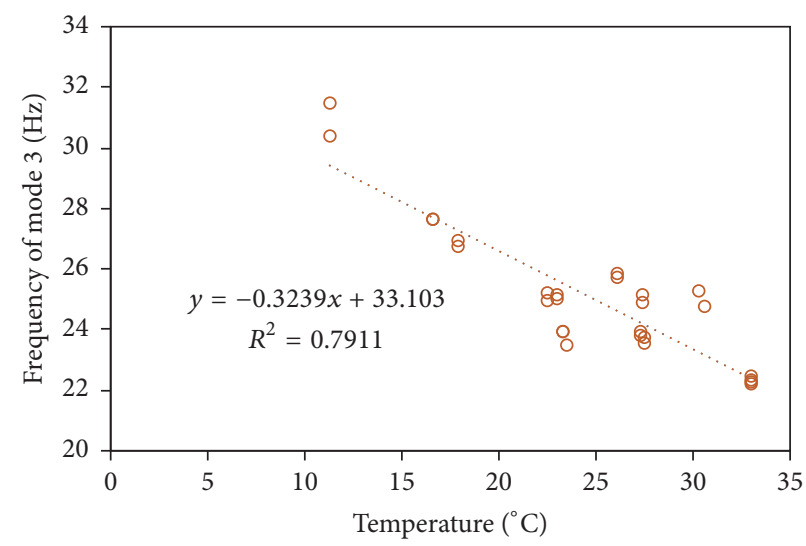

(c) Girder No. 3

FIGURE 9: ((a)-(c)) Relation of frequencies of mode 3 to temperature. 


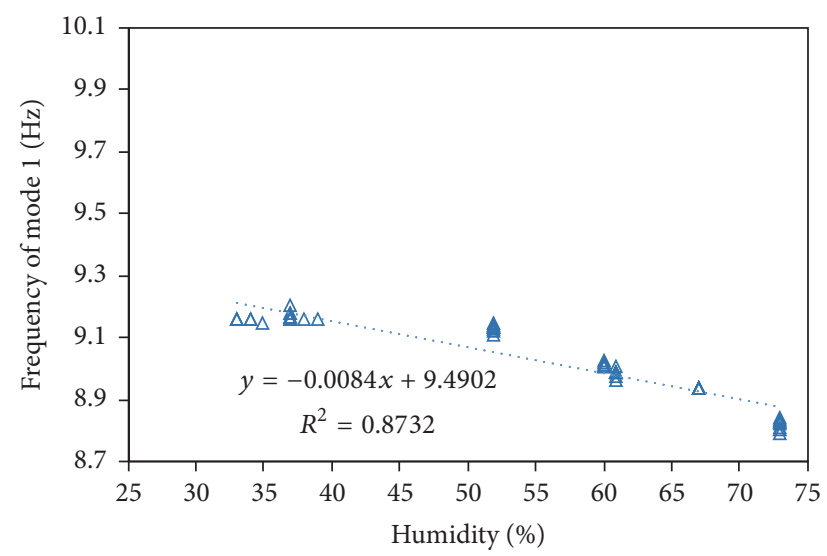

(a) Girder No. 1

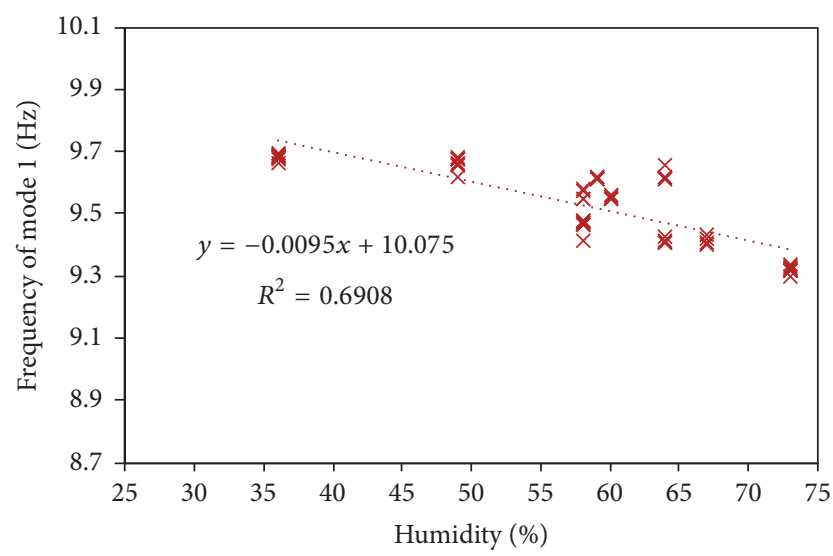

(b) Girder No. 2

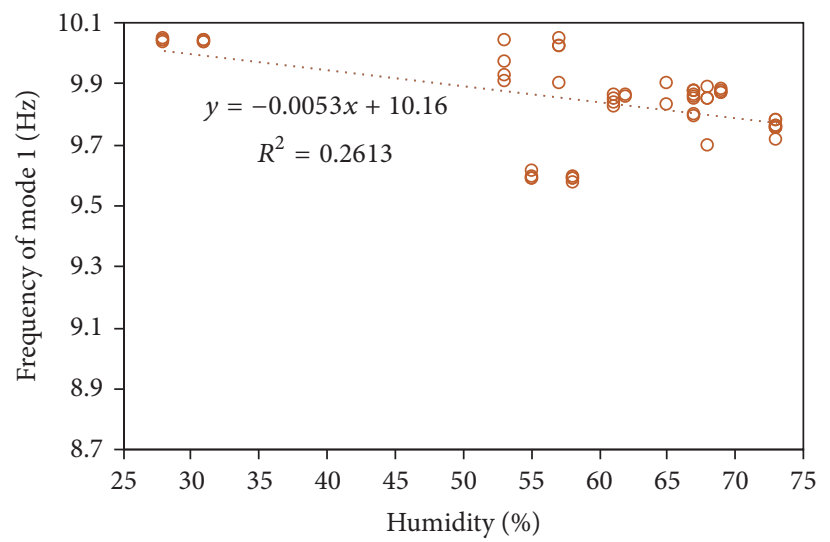

(c) Girder No. 3

Figure 10: ((a)-(c)) Relation of frequencies of mode 1 to humidity.

3.1.4. Evaluation of the Effects of ASR-Induced Deterioration. Another important result is the difference in the frequencies of the three girders over the monitoring period. For each measurement, the vibration test was replicated eight times in total, and the average values were calculated. Figures 13(a)-13(c) show the time histories of the average natural frequencies of the three modes over one and a half years. However, the frequencies of the torsional mode were similar. The differences in the measured frequencies of the three girders clearly manifested over time with regard to the two bending modes. Moreover, the bending frequency of girder No. 3 was the highest as compared to the results obtained for girders No. 1 and No. 2 at each measuring time. In terms of the first bending mode, the frequencies of girder No. 1 exhibited much lower values than those of the two other girders. In September 2016, as compared to the result obtained for girder No. 3, the frequencies of girders No. 1 and No. 2 were lower by $\sim 9.6$ and $\sim 4.5 \%$, respectively. With regard to the second bending mode, the frequencies of the three girders were approximately the same at the initial measurements because the differences in the identified data were obtained as approximately $0.06 \%$ in May 2015. Since November 2015, the difference became pronounced, and until the end of the monitoring period, the frequency of girder No. 3 was $\sim 4.54 \%$ greater than that of girder No. 2. Because the cross sections of the three girders were the same with fairly similar mixtures and were tested alternately in a short time during each measurement, the difference in the natural frequency of the bending modes was probably not due to the changes in temperature and humidity. One of the possible reasons for the same is that girders No. 1 and No. 2 were affected by the ASR deteriorations, thereby forming many cracks that propagated longitudinally on the top and both side surfaces of the girders and leading to the decrease in Young's modulus of concrete. Sugiura et al. [20] studied girders No. 2 and No. 3 and showed that the expansion rate of concrete in the transverse direction, which was the primary cause of the longitudinal ASR-induced cracks, increased significantly since early October 2015 in girder No. 2. In addition, fracture mechanics states that the occurrence of a crack in a structure causes a local flexibility influencing its dynamic responses [21]. Dimarogonas [21] proposed that, for a small crack depth, the local flexibility $(\Delta c)$ is a function of $(a / h)^{2}$, where $a$ is the crack depth and $h$ is the height of the beam. Assuming that the intact beam has a flexibility $(c)$, the total flexibility $(C)$ after the formation of a crack and the corresponding structural stiffness $(K)$ can be obtained as follows.

$$
\begin{aligned}
& C=c+\Delta c, \\
& K=\frac{1}{C}=\frac{1}{c+\Delta C}=\frac{1}{c+\lambda(a / h)^{2}},
\end{aligned}
$$




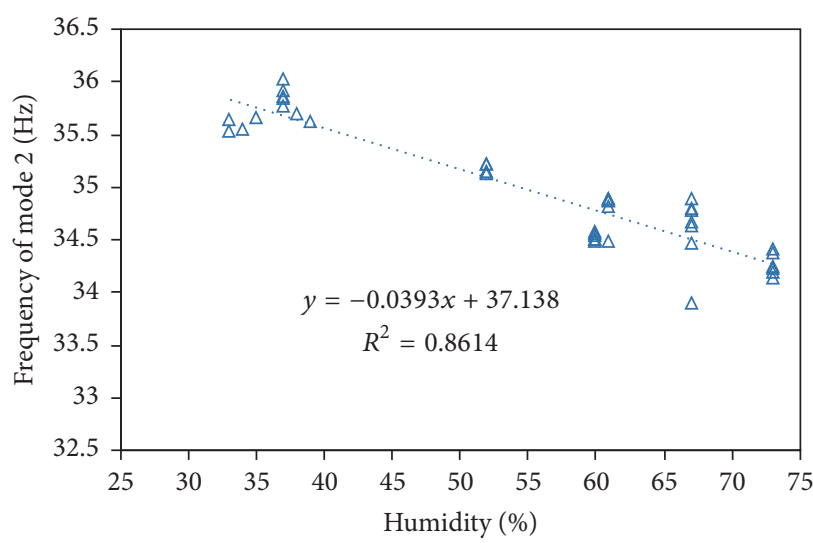

(a) Girder No. 1

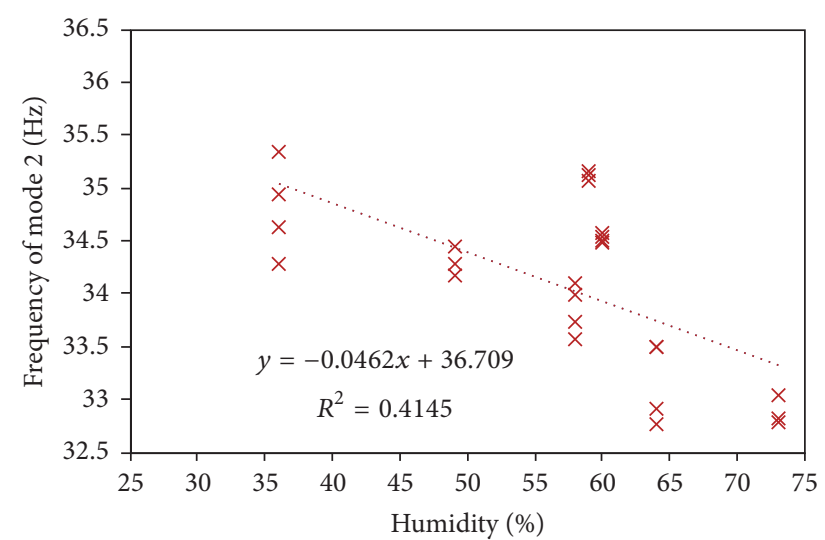

(b) Girder No. 2

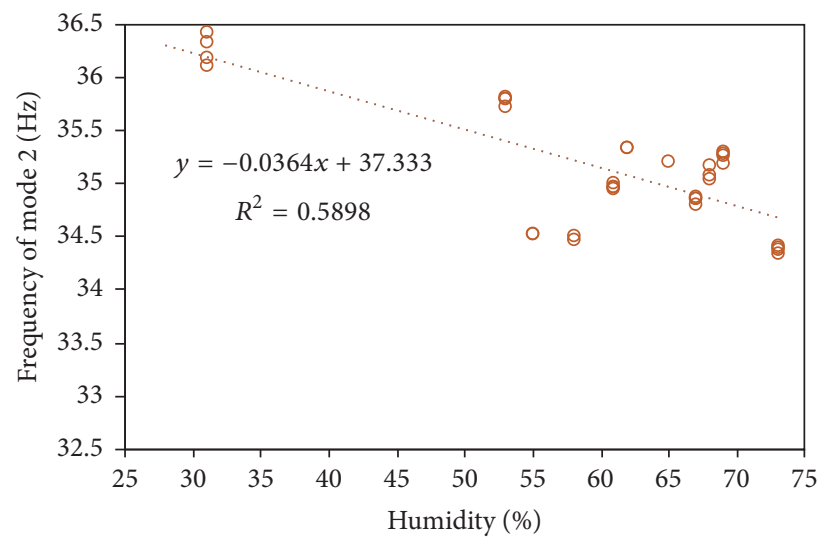

(c) Girder No. 3

Figure 11: ((a)-(c)) Relation of frequencies of mode 2 to humidity.

where $\lambda=1.86(6 \pi h / E I)$ is a constant. Likewise, the radian frequency $\left(\omega_{n}\right)$ of the crack-free beam will vary with respect to $\Delta \omega_{n}$, and the total radian frequency will be $\omega_{n}^{\prime}=\omega_{n}+\Delta \omega_{n}$. In addition, because the natural frequency $\left(f_{n}\right)$ can be obtained by dividing $\omega_{n}$ by $2 \pi$, the change $\left(\Delta f_{n}\right)$ due to the formation of the crack should be equal to $\Delta \omega_{n} / 2 \pi$. For a single degree of freedom oscillator, the natural frequency depends on the system properties such as mass $(m)$ and stiffness $(K)$. Given that there is a small crack in the structure, the radian frequency $\left(\omega_{n}^{\prime}\right)$ can be defined using the following relationship.

$$
\begin{aligned}
\left(\omega_{n}^{\prime}\right)^{2} & =\left(\omega_{n}+\Delta \omega_{n}\right)^{2}=\omega_{n}{ }^{2}+2 \omega_{n} \Delta \omega_{n}+\Delta \omega_{n}{ }^{2}=\frac{K}{m} \\
& =\frac{1}{m\left(c+\lambda(a / h)^{2}\right)}=\frac{1}{m c\left(1+(\lambda / c)(a / h)^{2}\right)} .
\end{aligned}
$$

Assuming that $(\lambda / c)(a / h)^{2}=\Delta c / c$ is much less than 1 and neglecting the higher order terms $\Delta \omega_{n}{ }^{2}$, the following equation can be obtained.

$$
\omega_{n}^{2}+2 \omega_{n} \Delta \omega_{n}=\frac{1}{m c}-\frac{\lambda}{c}\left(\frac{a}{h}\right)^{2}
$$

Therefore, the changes in the radian frequency $\left(\Delta \omega_{n}\right)$ and natural frequency $\left(\Delta f_{n}\right)$ can be obtained using (7) and (8), respectively.

$$
\begin{aligned}
\Delta \omega_{n} & =-\frac{\lambda}{2 \omega_{n} c}\left(\frac{a}{h}\right)^{2}, \\
\Delta f_{n} & =-\frac{\lambda}{4 \pi \omega_{n} c}\left(\frac{a}{h}\right)^{2} .
\end{aligned}
$$

Accordingly, the relationship between the occurrence of cracks and the decrease in the natural frequency is proved. Moreover, because the expansion of the ASR was effectively suppressed by the fly ash, the frequency variation of girder No. 3 was largely due to the environmental effects. Within one and a half years of investigation, as the ambient temperature and humidity varied by approximately $21.55^{\circ} \mathrm{C}$ and $45 \%$, respectively, the bending modal frequencies of girder No. 3 varied in the range of $\sim 3-5 \%$, which is considerable compared to those due to the structural damage. Hence, the effects of the environmental conditions should be considered carefully when using the variation in the vibrational frequency to evaluate the health of structures.

3.2. Variation in Damping Ratio. The damping ratio was extracted from the measured data to examine the 
TABLE 11: Coefficients of linear regression model (damping ratio temperature) of girder No. 3 .

\begin{tabular}{lcccccc}
\hline Mode & Intercept $\alpha_{0}$ & Gradient $\beta_{t}$ & Std. Error $\sigma_{\varepsilon_{f}}$ & $\sigma_{\varepsilon_{f}} / \alpha_{0}(\%)$ & $\beta_{t} / \alpha_{0}(\%)$ & Coefficient of determination $R^{2}$ \\
\hline 1 & 0.0145 & -0.0001 & 0.0012 & 8.1397 & -0.4504 & 0.0300 \\
2 & 0.0214 & -0.0002 & 0.0014 & 6.4610 & -0.7625 & 0.2159 \\
3 & 0.1010 & -0.0007 & 0.0079 & 7.8235 & -0.7360 & 0.1843 \\
\hline
\end{tabular}

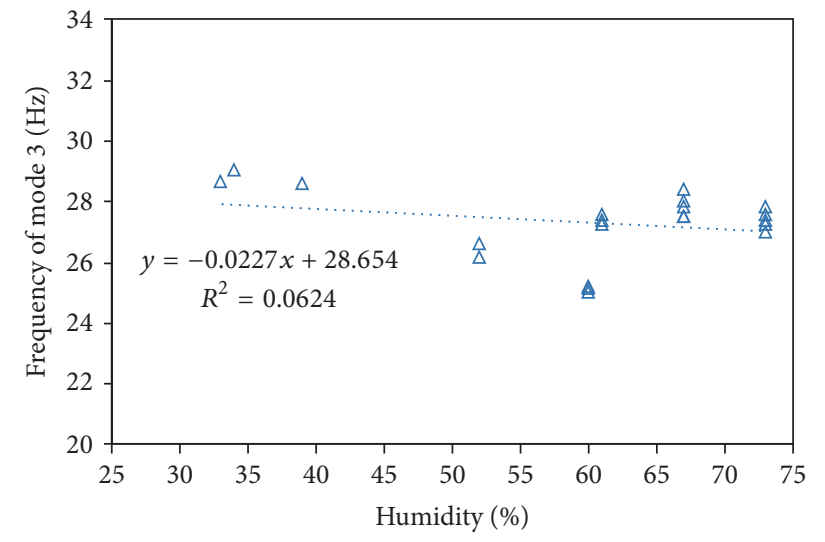

(a) Girder No. 1

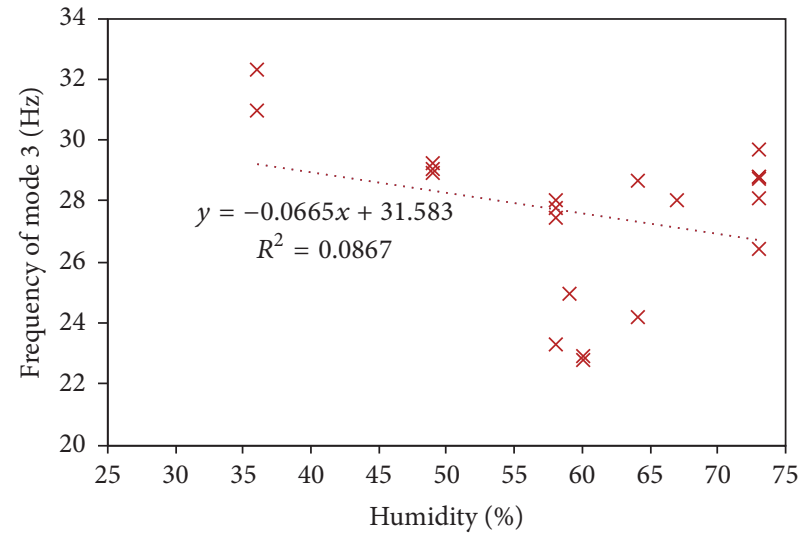

(b) Girder No. 2

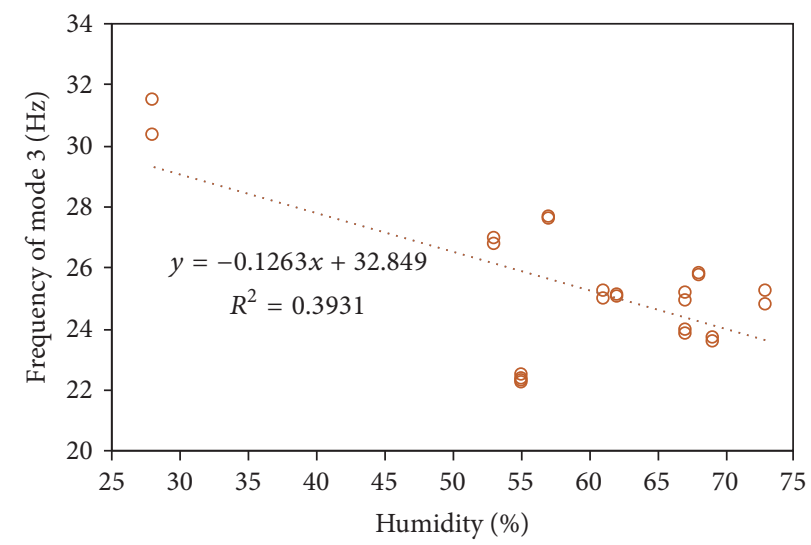

(c) Girder No. 3

FigURE 12: ((a)-(c)) Relation of frequencies of mode 3 to humidity.

changes due to the ambient temperature and humidity. Figures 14(a)-14(c) and 15(a)-15(c) show the identified damping ratios of the three vibration modes of girder No. 3 with respect to the ambient temperature and humidity, respectively. Except for Figure 15(a), which shows a weak positive relationship with the humidity, the rest of the figures demonstrate that the damping ratios relatively decrease with the increases in the environmental parameters.

Using R [18], the regression models were then developed to evaluate the linear correlations between the variables. A governing equation of the linear regression model of the damping ratio $(d)$ as a function of the temperature $(T)$ was proposed as follows.

$$
d=\alpha_{0}+\beta_{t} T+\varepsilon_{f}
$$

where $d$ is the damping ratio, $\alpha_{0}$ and $\beta_{t}$ are the intercept and the gradient, respectively, and $\varepsilon_{f}$ is the regression error.
Table 11 lists the results of the statistical analysis for girder No. 3. The gradients were obtained, respectively, as -0.0001 , -0.0002 , and -0.0007 for the three modes, indicating that the damping ratios increased slightly with the decrease in the temperature as described in Figures 16(a)-16(c). In these figures, the average values were calculated for each measurement and plotted to find the pattern of the damping variation over time. However, the coefficients of determination $R^{2}$ were estimated at low values, which were $0.03,0.2159$, and 0.1843 for modes 1, 2, and 3, respectively. Additionally, the standard deviation of the errors occupied large proportions of the intercept, which were above $\sim 6.4 \%$. Attempts were made to evaluate the relationship between the damping ratios and ambient humidity. Another linear regression equation was similarly developed for the investigation. Table 12 lists the coefficients of the linear regression model of the damping ratio with respect to the humidity. Because the $R^{2}$ statistics 
TABLE 12: Coefficients of linear regression model (damping ratio humidity) of girder No. 3.

\begin{tabular}{lcccccc}
\hline Mode & Intercept $\alpha_{0}$ & Gradient $\beta_{t}$ & Std. Error $\sigma_{\varepsilon_{f}}$ & $\sigma_{\varepsilon_{f}} / \alpha_{0}(\%)$ & $\beta_{t} / \alpha_{0}(\%)$ & Coefficient of determination $R^{2}$ \\
\hline 1 & 0.0120 & 0.00002 & 0.0015 & 12.5748 & 0.1482 & 0.0094 \\
2 & 0.0224 & -0.00008 & 0.0018 & 8.2411 & -0.3624 & 0.2024 \\
3 & 0.0878 & -0.00011 & 0.0111 & 12.6373 & -0.1255 & 0.0163 \\
\hline
\end{tabular}

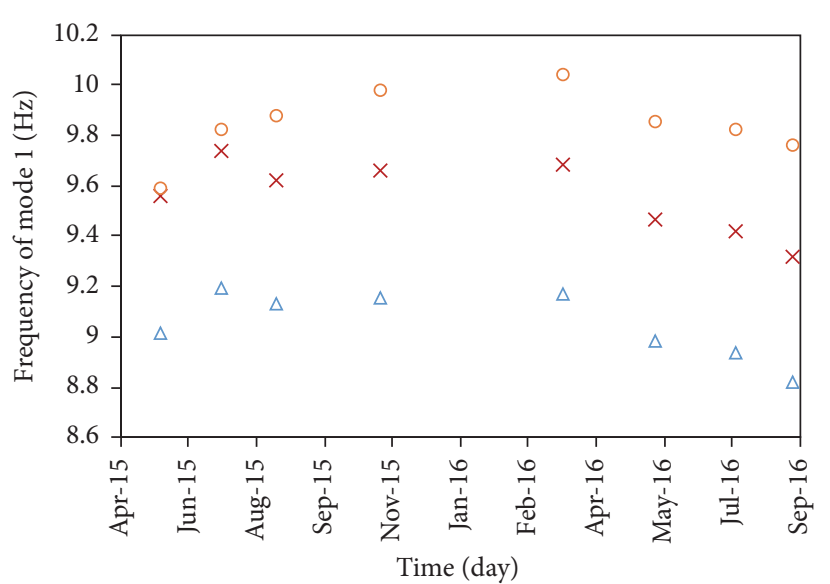

$\triangle$ Girder No. 1

$\times$ Girder No. 2

- Girder No. 3

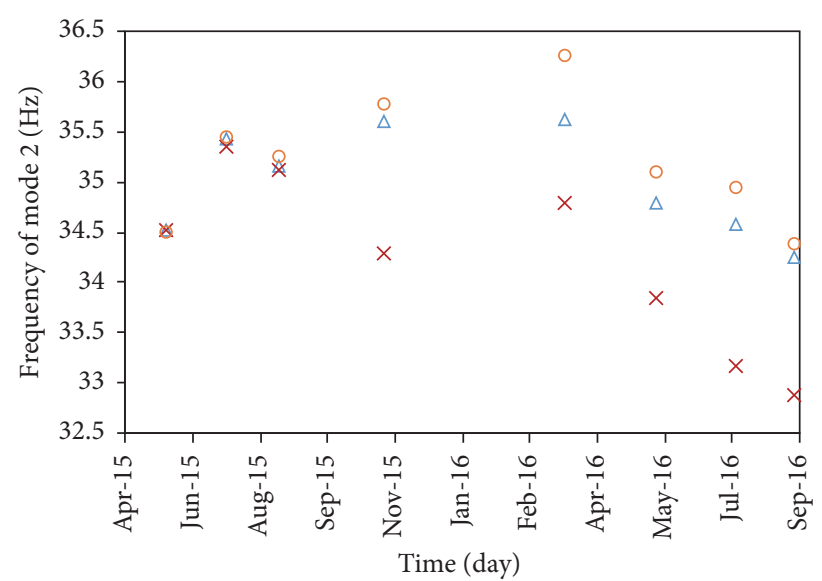

$\triangle$ Girder No. 1

$\times$ Girder No. 2

- Girder No. 3

(a) The 1st bending mode

(b) The 2nd bending mode

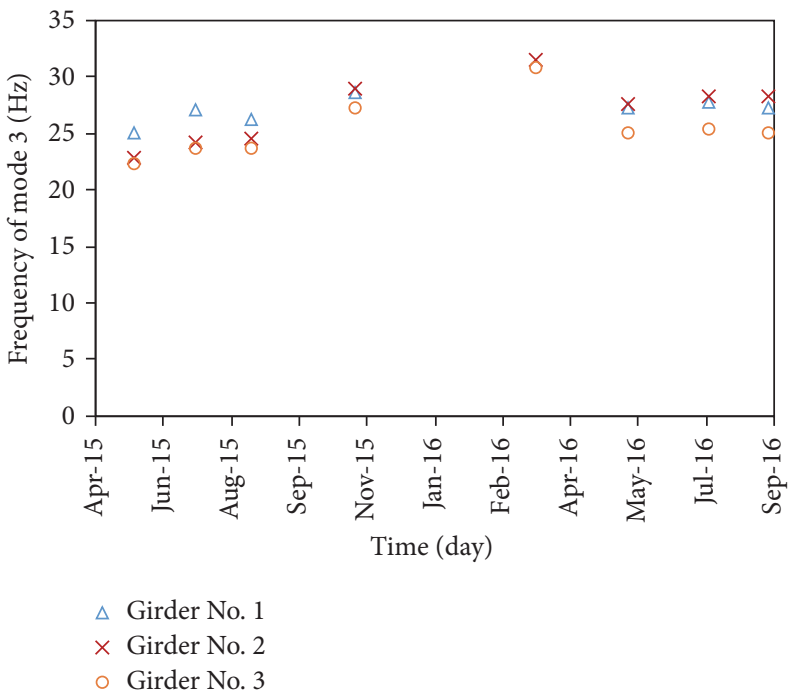

(c) The 1st torsional mode

FiguRE 13: ((a)-(c)) Difference in natural frequencies of three girders.

were low and the identified noises were rather high at approximately $12 \%$ for modes 1 and 3 and $\sim 8 \%$ for mode 2 , the results were similar to those obtained with respect to the ambient temperature. In addition, a multiple linear regression model was considered to analyze the variation in the damping ratio under the combined effect of the ambient temperature and humidity. As an outcome of the model for girder No. 3 , the $R^{2}$ statistics were estimated at $0.1843,0.2499$, and 0.2539 for the three vibration modes, and the corresponding correlation coefficients $R$ were obtained, respectively, as
$0.4293,0.4999$, and 0.5039 , which were quite higher than the ones obtained for the single linear models. Based on the above statistical parameters, the effects of the measured humidity and temperature on the change in the damping ratio were evaluated as weak correlations in this study. Similar outcomes were found with respect to the damping ratios of the other two girders. Thus, the changes in the damping ratio were not only affected by the ambient temperature and humidity but also governed by other factors. However, it is difficult to determine the damping ratio with sufficient accuracy to 


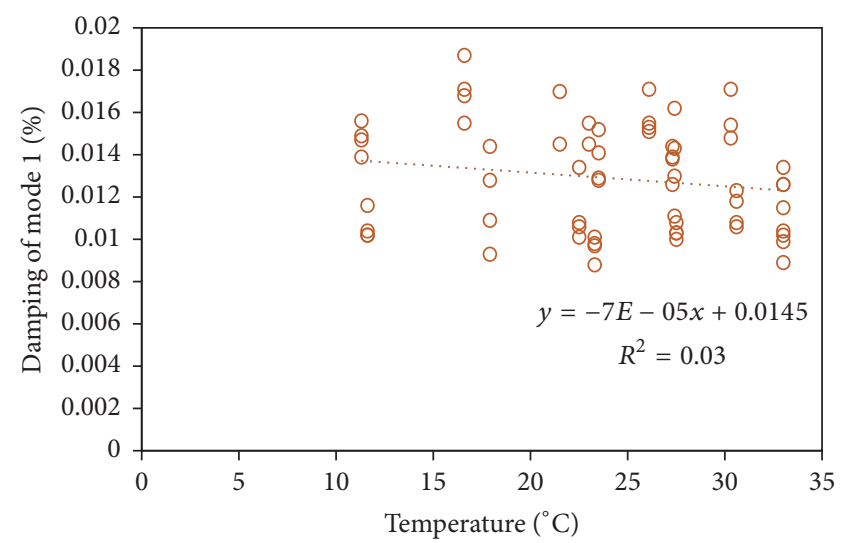

(a) Mode 1

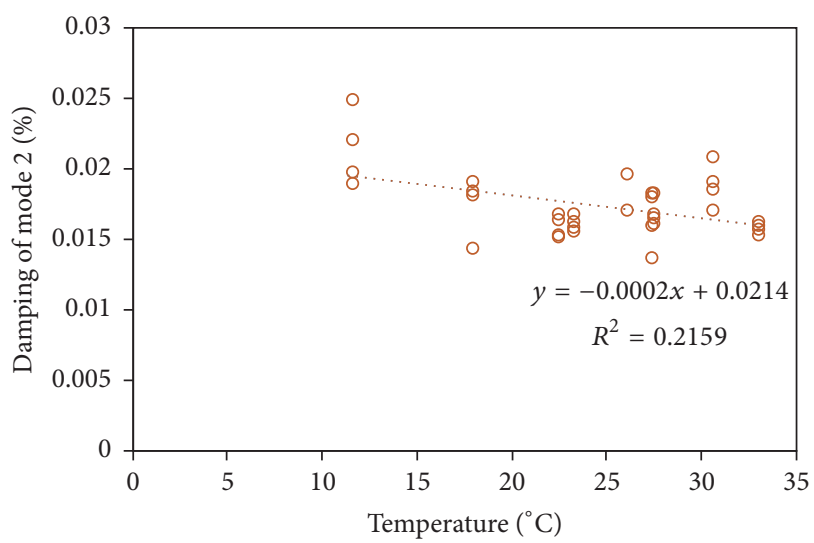

(b) Mode 2

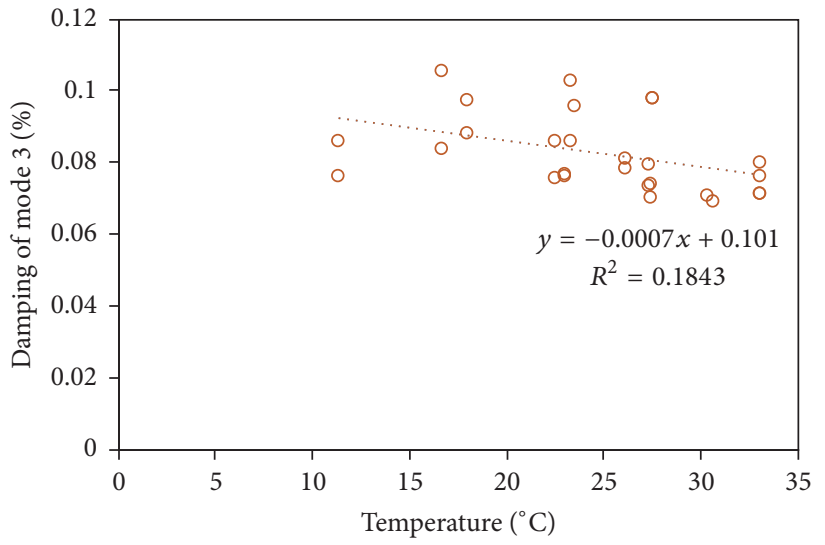

(c) Mode 3

FIGURE 14: ((a)-(c)) Relation of damping ratios of girder No. 3 to temperature.

estimate the correlations with the temperature, as reported in previous studies $[8,19,21]$.

In addition, the cracks in a structure not only affect the structural stiffness $[8,22,23]$ but also lead to variations in the structural damping ratio because of the appearance of plastic zones along the edges of the cracks [21]. Curadelli et al. [24] showed the difference in the instantaneous damping coefficient between the healthy and damaged condition of a reinforced concrete beam. They clearly demonstrated that the variation in the damping was considerable and the instantaneous damping coefficients of the undamaged state were lower than of the measured ones at the final loading step with respect to all the vibration amplitudes. In the present study, the difference in the damping ratios of the three girders over the monitoring period was analyzed accordingly. Figures $17(a)-17(c)$ show the time histories of the average damping coefficients over the follow-up period. Apart from the first torsional mode (mode 3), wherein the difference in the amplitude was insignificant, the damping ratios of the other modes changed considerably, representing the difference between the girders. With regard to the damping of the first bending mode (mode 1), all the identified values of girder No. 1 were clearly higher than that of girders No. 2 and No. 3, which were similar in terms of the amplitude. With regard to the second bending mode (mode 2), the damping ratios of the three girders were largely equal at the three initial measurements. The differences became apparent since November 2015. From the data of September 2016, the average damping ratios of girders No. 2 and No. 1 were approximately 2 and 1.5 times, respectively, greater than the identified value of girder No. 3. As the correlations with the changes in the ambient environmental parameters were low, the difference in the damping coefficients in the two bending modes of the three girders was probably due to the increase in the longitudinal crack propagation due to the ASR-induced expansion, which led to the increase in the number of plastic zones in girders No. 1 and No. 2.

3.3. Variation in Mode Shapes. In this study, the variations in the mode shape due to the environmental effects were examined using the modal assurance criterion (MAC) [25], which is a simple index used to characterize the effects of the damage on the mode shapes. The MAC reflects the degree of relationship between the two modal curves, which were extracted from the acceleration data obtained at different states of a structure. The MAC can be computed as follows.

$$
\text { MAC }=\frac{\left(\sum_{j=1}^{n} \psi_{I j} \psi_{D j}\right)^{2}}{\sum_{j=1}^{n} \psi_{I j}^{2} \sum_{j=1}^{n} \psi_{D j}^{2}},
$$




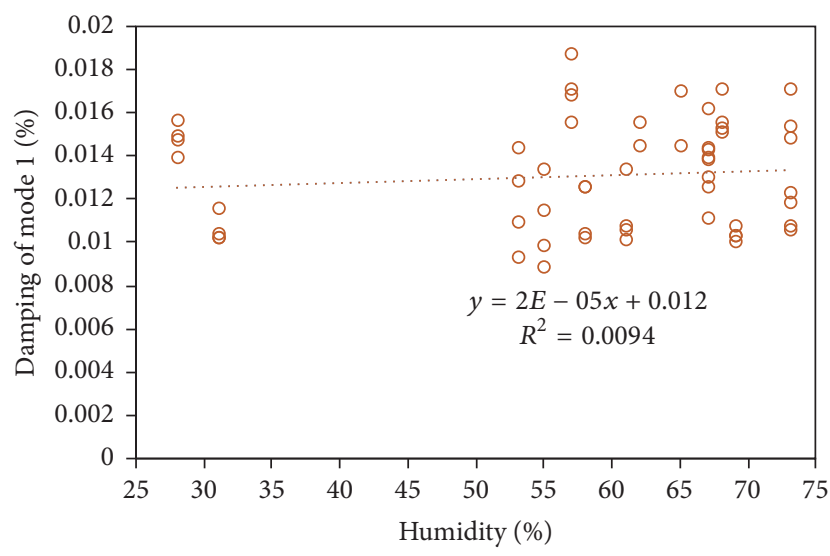

(a) Mode 1

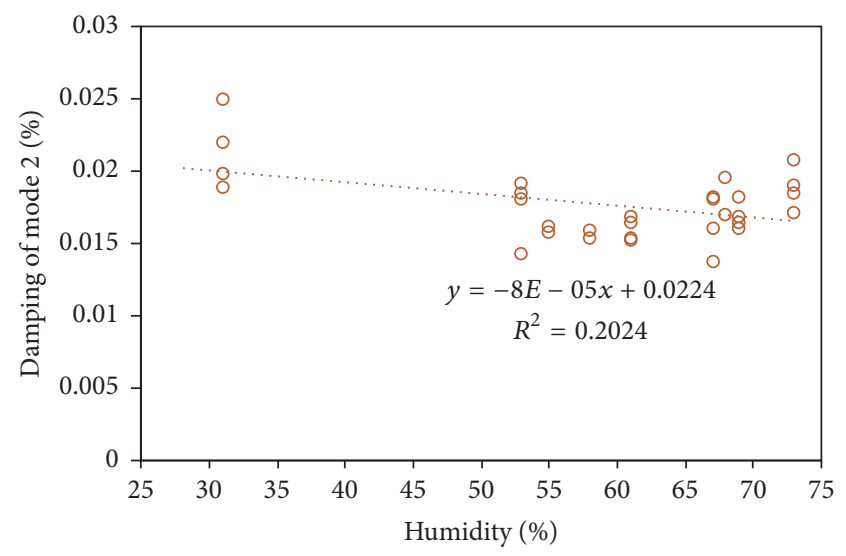

(b) Mode 2

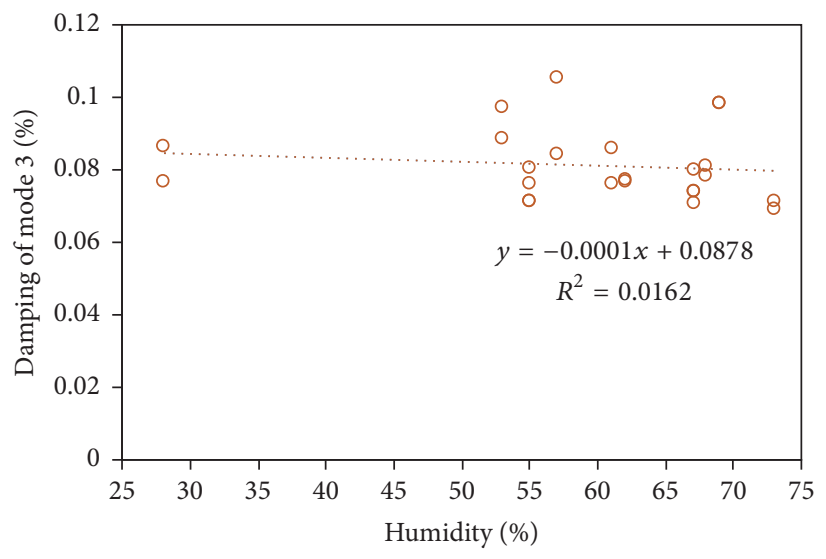

(c) Mode 3

Figure 15: ((a)-(c)) Relation of damping ratios of girder No. 3 to humidity.

where $\psi_{I j}$ and $\psi_{D j}(j=1 \sim n+1)$ are the identified mode shape values at the $j$ th point of the intact and damaged modal vectors, respectively, and $n$ indicates the number of observation points of a vibration mode. In the case wherein there are no differences due to the structural change in the two sets of the mode shapes, the MAC value would be equal to unity. However, the MAC value might decrease in amplitude to zero if any variation exists in the structural properties, thereby reducing the correlation degree between the two mode shapes. To determine the MAC, the analytical mode shapes, as shown in Figures 18(a) and 18(b), were used as reference lines. Figures 19(a), 19(b), 20(a), and 20(b) show the identified MAC values of the two bending modes with respect to the temperature and humidity. Figures 19(a) and 19(b) show that the scatters seen in all the MAC values are significant with no notable pattern reflecting the variation in the amplitude with respect to the ambient temperature. The obtained values are higher than 0.97 and 0.9 for the two bending modes, which are approximately close to unity. Similarly, Figures 20(a) and 20(b) show no clear trend in the MAC changes due to the measured humidity. Because all the coefficients of determination obtained from the multiple linear regression analysis were estimated to be lower than 0.2 , the correlation levels with the temperature and humidity were weak in terms of the MAC values of the two bending modes. Although it is widely accepted that the MAC is a useful indicator of the changes in the structural performance, it is not sensitive to the uniform changes throughout the structure [8]. In fact, the ambient temperature and humidity affect the entire girder uniformly [8], and consequently, the effects of the environmental conditions on the MAC values were observed at low levels. The results obtained in this study help confirm this observation. Figures 21 (a) and 21(b) show the time histories of the identified MAC values of the first and second bending modes, respectively, to compare between the three girders over the monitoring period. With regard to mode 1, the MAC values of girders No. 1 and No. 2 are relatively lower than those of girder No. 3. However, no significant separation in the amplitude was observed. A similar observation regarding mode 2 was found for all the girders. Hence, no clear difference was found in the magnitude of the MAC values considered in this study. Because the torsional mode could not be estimated precisely for all the girders as mentioned in the previous section, its MAC values are not reported in this section.

\section{Numerical Modeling}

4.1. Eigenvalue Structural Analysis. To evaluate the accuracy of the measurement, a three-dimensional (3D) model was 


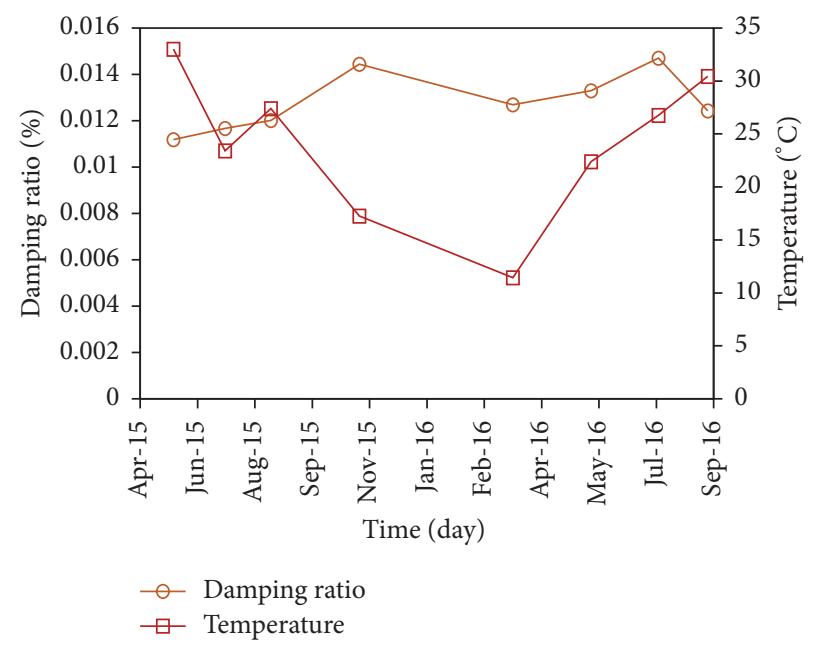

(a) Mode 1

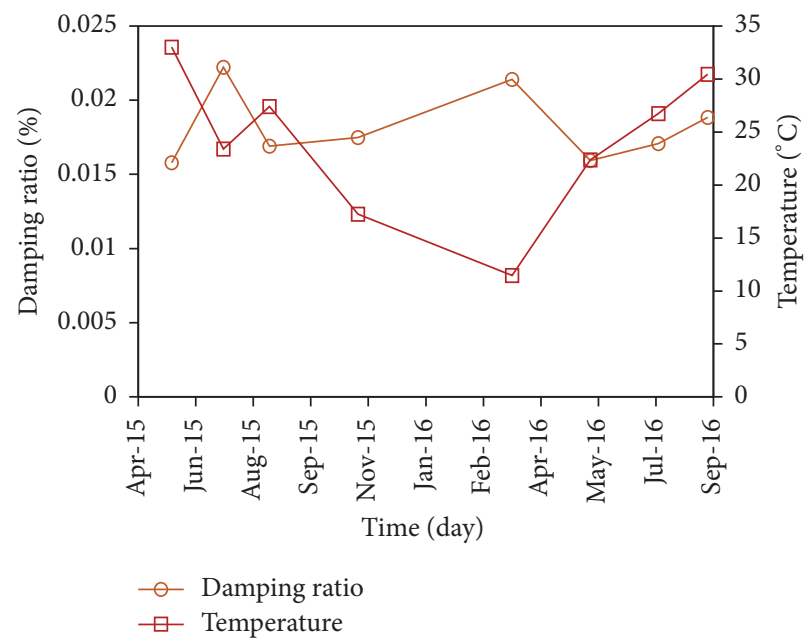

(b) Mode 2

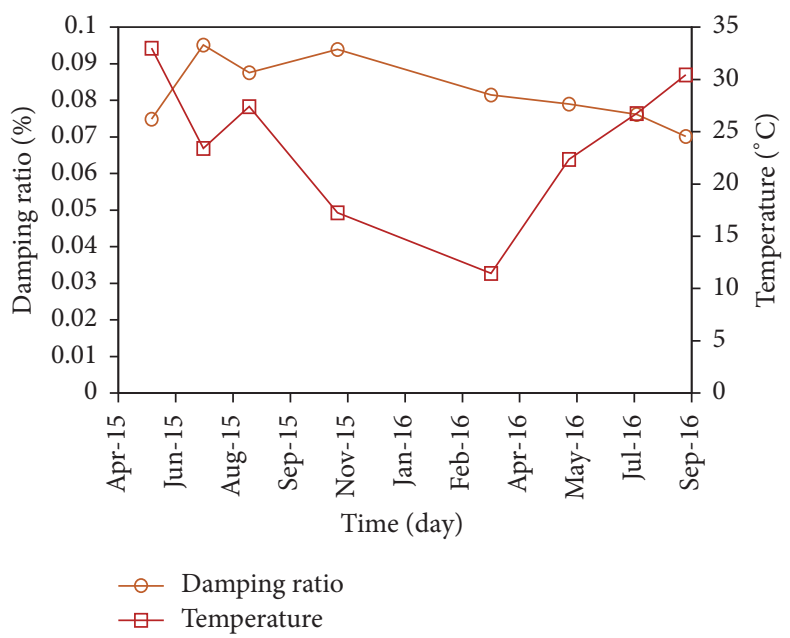

(c) Mode 3

FIGURE 16: ((a)-(c)) Variations in average damping ratios of girder No. 3 over one and a half years.

produced using FX+ for DIANA, which is a commercially available program for FE analysis. The properties and boundary conditions of the numerical model were the same as those of the actual PC girder. Figure 22 shows the diagram of a 3D model used for the eigenvalue structural analysis in DIANA [26]. The objective model was a PC girder supported by two points with a span length of $9200 \mathrm{~mm}$. As a PC girder, it contained 16 PC steel strands (SWPR7BL1S $12.7 \mathrm{~mm}$ ). The strands had D10-type stirrups arranged around them. The PC strands and stirrups were modeled as bars in the beam elements. The bonding forces between the concrete and strands were assumed complete. Table 13 lists the parameters of the concrete for the analysis. Moreover, the stirrups were assumed as linear elastic materials with Young's modulus $E_{c}=$ $210000 \mathrm{~N} / \mathrm{mm}^{2}$ and Poisson's ratio $v=0.3$. Moreover, the PC steel material was considered made of steel with Young's modulus $E_{c}=210000 \mathrm{~N} / \mathrm{mm}^{2}$ and Von Mises yield stress $\sigma_{y}=1580 \mathrm{~N} / \mathrm{mm}^{2}$. The mass density for the steel materials was selected as $7.7 e-9 \mathrm{~T} / \mathrm{mm}^{3}$. Figures $23(\mathrm{a})$ and $23(\mathrm{~b})$ show
TABLE 13: Material parameters of concrete for eigenvalue analysis.

\begin{tabular}{lccc}
\hline Young's modulus & $E_{c}$ & 38700 & $\mathrm{~N} / \mathrm{mm}^{2}$ \\
Poisson's ratio & $\nu$ & 0.16 & \\
Mass density & $\rho$ & $2.45 e-9$ & $\mathrm{~T} / \mathrm{mm}^{3}$ \\
\hline
\end{tabular}

the modal shapes of the two bending modes of girder No. 3 and the corresponding frequencies, which are quite similar to the measured modes shown in Figures 6(a) and 6(b), respectively.

4.2. Validation. Over the years, many researchers have proved that the temperature change affects not only the thermal properties but all the mechanical properties of the concrete such as the compressive strength, tensile strength, Young's modulus, and stress-strain relationship [27-29]. In particular, the variation in the compressive strength of the concrete at elevated temperatures (from $100^{\circ} \mathrm{C}$ to $1000^{\circ} \mathrm{C}$ ) 


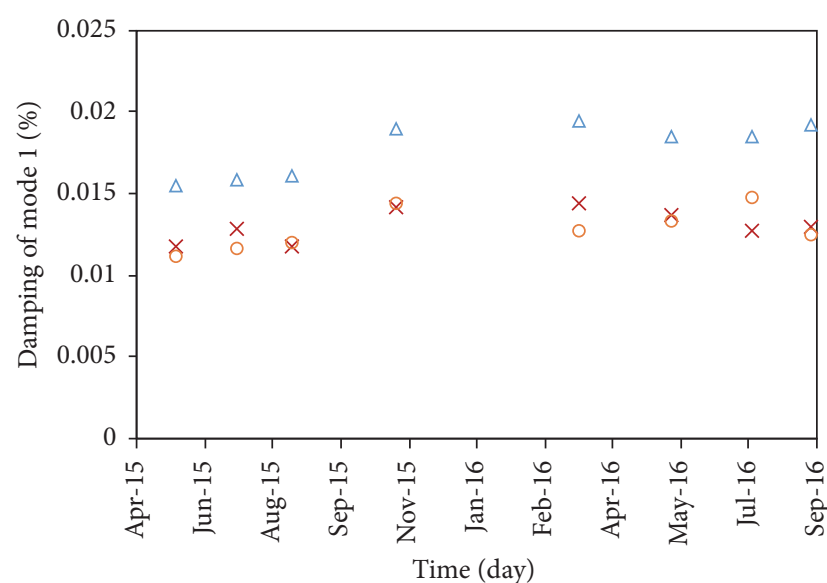

$\triangle$ Girder No. 1

$\times$ Girder No. 2

- Girder No. 3

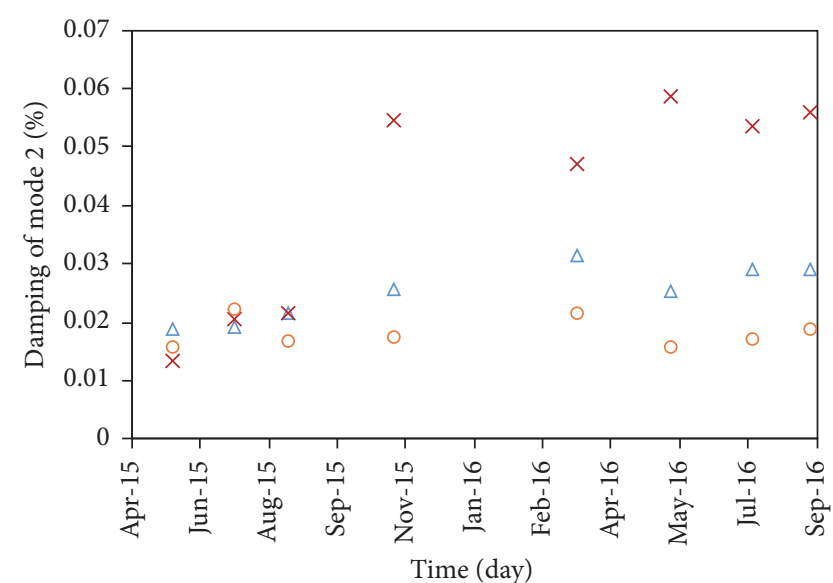

$\triangle$ Girder No. 1

$\times$ Girder No. 2

- Girder No. 3

(a) Mode 1

(b) Mode 2

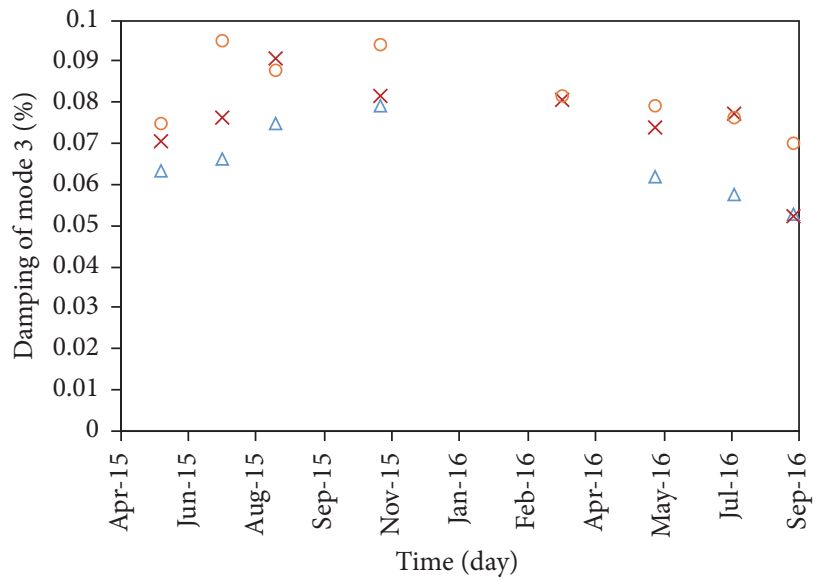

$\triangle$ Girder No. 1

$\times$ Girder No. 2

○ Girder No. 3

(c) Mode 3

FIGURE 17: ((a)-(c)) Difference in damping ratios of three girders.

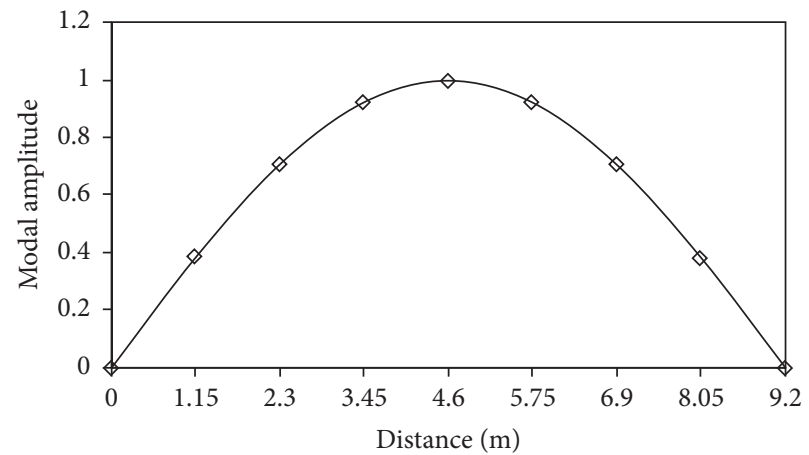

(a) The 1st bending mode (mode 1)

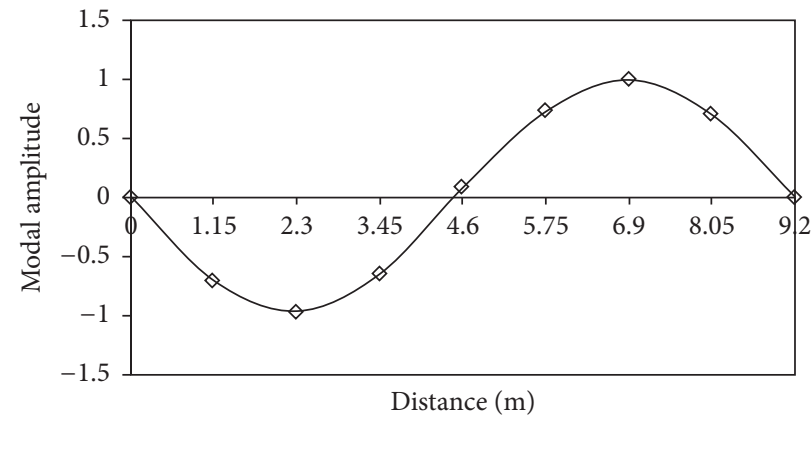

(b) The 2nd bending mode (mode 2)

Figure 18: ((a)-(b)) Two analytical mode shapes. 


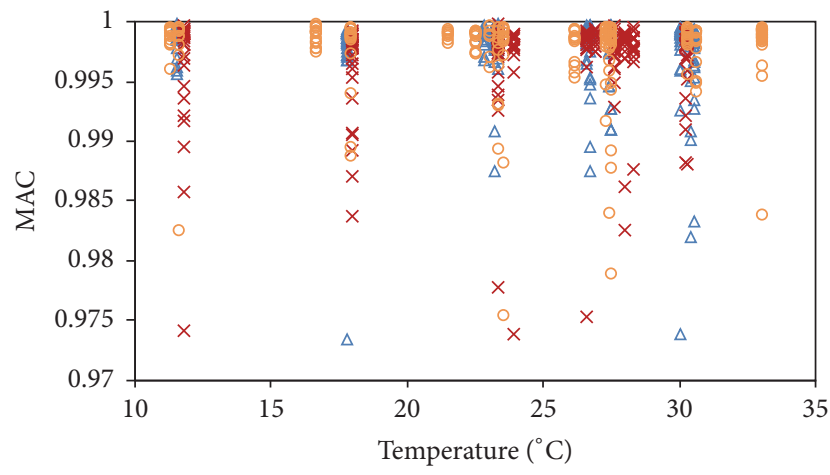

$\triangle$ Girder No. 1

$\times$ Girder No. 2

- Girder No. 3

(a) The 1st bending mode (mode 1)

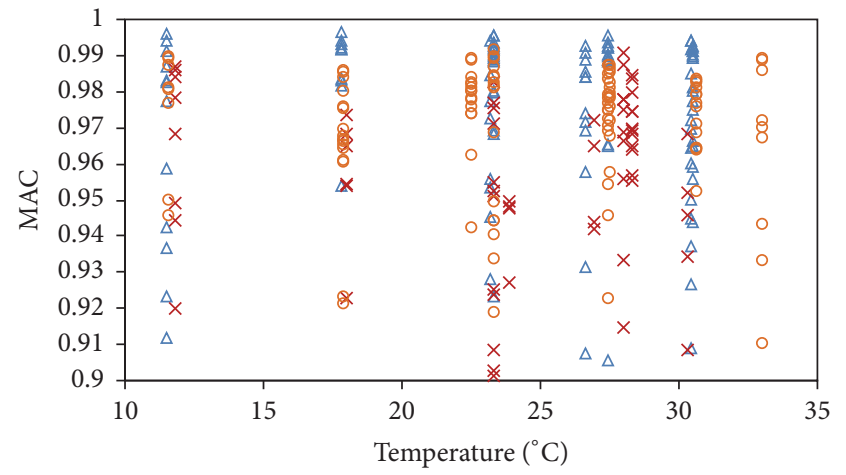

$\triangle$ Girder No. 1

$\times$ Girder No. 2

- Girder No. 3

Figure 19: ((a)-(b)) Identified MAC values of two bending modes versus measured ambient temperature.
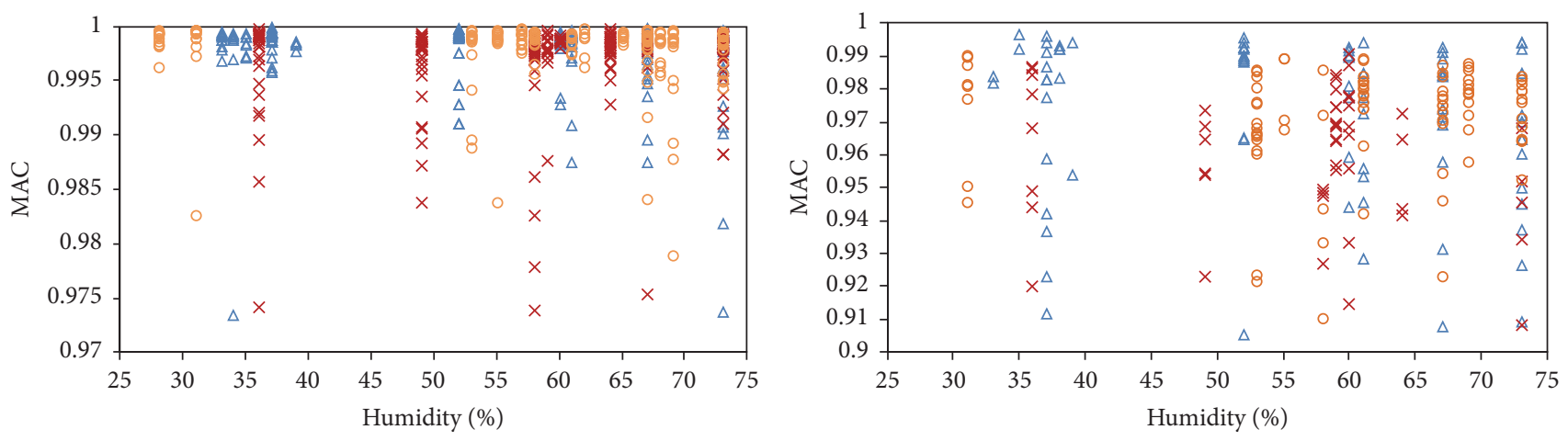

$\triangle$ Girder No. 1

$\triangle$ Girder No. 1

$\times$ Girder No. 2

$\times$ Girder No. 2

- Girder No. 3

- Girder No. 3

(a) The 1st bending mode (mode 1)

(b) The 2nd bending mode (mode 2)

FIGURE 20: ((a)-(b)) Identified MAC values of two bending modes versus measured humidity.
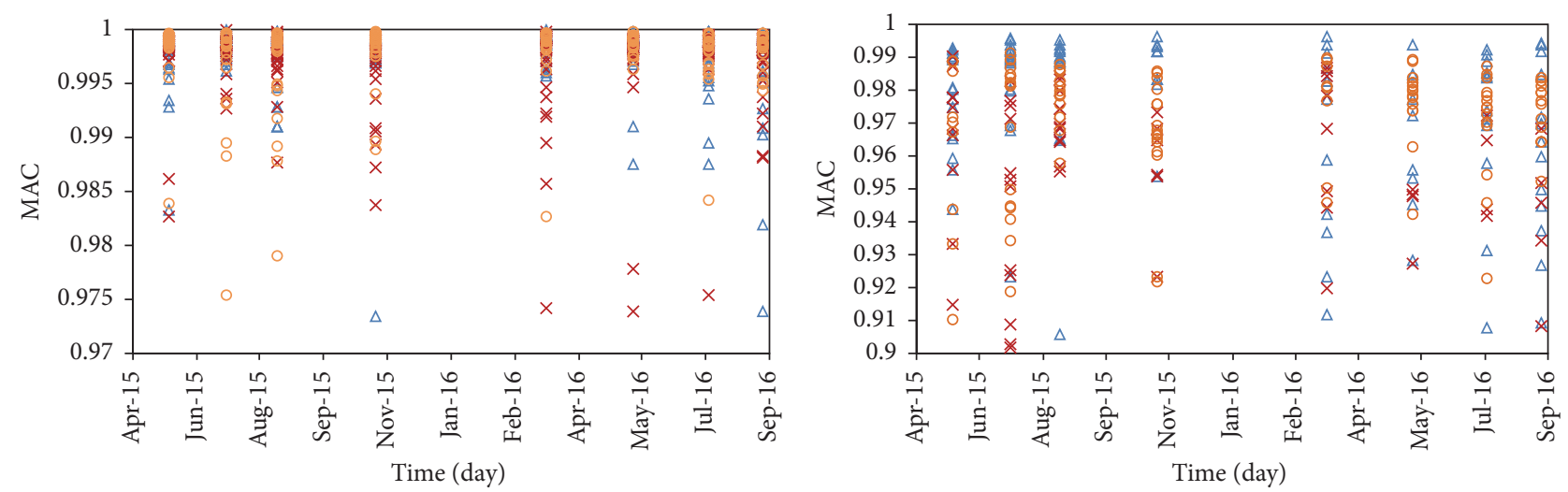

$\triangle$ Girder No. 1

$\triangle$ Girder No. 1

$\times$ Girder No. 2

$\times$ Girder No. 2

- Girder No. 3

- Girder No. 3

(a) The 1st bending mode (mode 1)

(b) The 2nd bending mode (mode 2)

Figure 21: ((a)-(b)) Time histories of MAC values for three girders. 
TABLE 14: Numerical analysis and measured results of two bending modal frequencies.

\begin{tabular}{|c|c|c|c|c|c|c|}
\hline \multirow[b]{2}{*}{$\begin{array}{l}\text { Time } \\
\text { Month }\end{array}$} & \multirow{2}{*}{$\begin{array}{c}\text { Average } \\
\text { temperature } \\
{ }^{\circ} \mathrm{C}\end{array}$} & \multirow{2}{*}{$\begin{array}{l}\text { Young's modulus } \\
\mathrm{N} / \mathrm{mm}^{2}\end{array}$} & \multicolumn{2}{|c|}{ Bending 1st mode } & \multicolumn{2}{|c|}{ Bending 2nd mode } \\
\hline & & & $\begin{array}{c}\text { Experiment } \\
\mathrm{Hz}\end{array}$ & $\begin{array}{c}\text { Analysis } \\
\mathrm{Hz}\end{array}$ & $\begin{array}{c}\text { Experiment } \\
\mathrm{Hz}\end{array}$ & $\begin{array}{c}\text { Analysis } \\
\mathrm{Hz}\end{array}$ \\
\hline 25-May-15 & 33.00 & 37191 & 9.593 & 9.576 & 34.506 & 37.054 \\
\hline 09-Jul-15 & 23.40 & 38305 & 9.822 & 9.713 & 35.453 & 37.583 \\
\hline 18-Aug-15 & 27.40 & 37841 & 9.874 & 9.656 & 35.261 & 37.363 \\
\hline 03-Nov-15 & 17.25 & 39019 & 9.981 & 9.799 & 35.787 & 37.918 \\
\hline 16-Mar-16 & 11.45 & 39693 & 10.041 & 9.880 & 36.266 & 38.231 \\
\hline 23-May-16 & 22.38 & 38424 & 9.855 & 9.727 & 35.112 & 37.639 \\
\hline 21-Jul-16 & 26.75 & 37916 & 9.826 & 9.665 & 34.957 & 37.399 \\
\hline 02-Sep-16 & 30.45 & 37487 & 9.759 & 9.613 & 34.385 & 37.195 \\
\hline
\end{tabular}

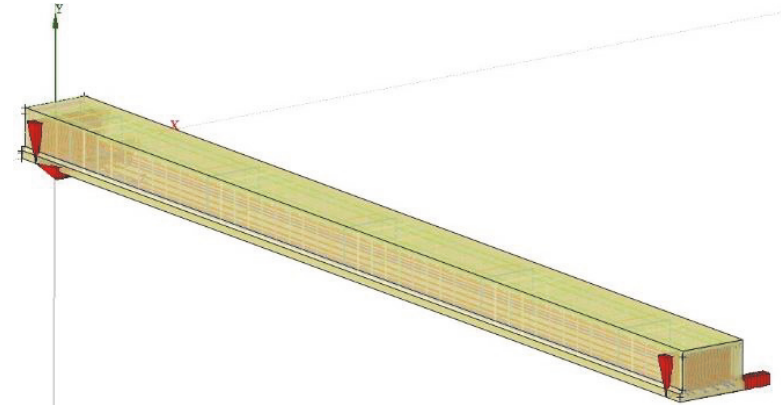

FIgURe 22: A 3D model of the PC girder.

was considerable, whereas the variation was less in the range of $0-100^{\circ} \mathrm{C}$ because the relative compressive strength was close to unity [27]. The change in the tensile strength of concrete is much lower than that of the compressive strength. Conversely, Young's modulus decreases significantly with the increase in the temperature [27]. Along with the increase in the atomic thermal variations, the volume expansion will occur in concrete when the temperature increases, thereby changing Young's modulus [29]. In addition, the effect of temperature on the properties of the steel materials was mentioned in the literature $[30,31]$. Because the temperatureinduced change in the material properties is complex, which is not of concern in this study, the primary focus in this section is on the effect of the temperature on Young's modulus of concrete, which leads to a variation in the natural frequency. Xia et al. [8] showed that the effects of the friction at the supports and the geometric change due to the temperature variation in the vibrational frequency were much lower than that of the temperature-induced variation in Young's modulus. Hence, the numerical analyses were extensively validated against the measured changes in the natural frequencies of the PC girders due to the ambient temperature which were conducted using FE commercial software. In this test, the 3D model of FX+ for DIANA described previously was used for the simulation. In this approach, a linear equation was employed wherein Young's modulus of concrete is considered a function of the temperature. At each measurement, Young's modulus with respect to the temperature was calculated and inputted to the DIANA model to obtain the modal parameters. The effect of temperature at the time of testing on Young's modulus of concrete, at an age of $28 \mathrm{~d}$ without the exchange of moisture, can be obtained using (11) [32] as follows.

$$
E_{c i}(T)=E_{c i}\left(1.06-\frac{0.003 T}{T_{0}}\right),
$$

where $T$ is the temperature of the material $\left({ }^{\circ} \mathrm{C}\right), E_{c i}$ is Young's modulus of concrete at $20^{\circ} \mathrm{C}, E_{c i}(T)$ is Young's modulus of concrete at temperature $T^{\circ} \mathrm{C}$, and $T_{0}=1^{\circ} \mathrm{C}$. The previous results show that girder No. 3 exhibited much lower levels of damage due to the ASR compared to the other two girders. The presence of a few cracks only slightly affected the vibrational responses because the correlation levels with the ambient temperature were clearly high for the three modal frequencies considered in this study. Therefore, the measured frequencies of girder No. 3 were employed as a comparison with the simulation results. Young's modulus of concrete at $20^{\circ} \mathrm{C}$ was assumed as $38700 \mathrm{~N} / \mathrm{mm}^{2}$, which was obtained from the compression tests conducted on concrete cores collected from the middle section of girder No. 3 along the direction perpendicular to the girder axis. Table 14 lists the analytical results of the two bending modal frequencies of girder No. 3. From this table, it is found that the numerical model yielded relatively similar values compared to the measurement. Therefore, the FE model can be calibrated to more closely match the experimental frequencies and provide more accurate predictions of the frequency in the future. There is a slight difference between the measurements and the analysis results because Young's moduli used in the numerical analysis might not reflect the real moduli of the entire girder, particularly because the girder is PC. The results of the coring test [33] showed that the mechanical properties of the concrete cores varied based on their collecting positions and directions. In particular, because of the effect of the restraining stress of the PC strands along with the low expansion rate of concrete, the concrete samples collected longitudinally from the central part exhibited lower compressive strengths compared to the samples collected from the transverse direction. When comparing the results obtained for the central and the end parts, the mechanical properties of the concrete cores of the end part are poorer than those of the central part. In addition, the ambient temperature, which was used as an input in the governing linear equation, did not significantly change the temperature of the girder instantaneously because of its large thermal mass. Therefore, the inputted temperature 


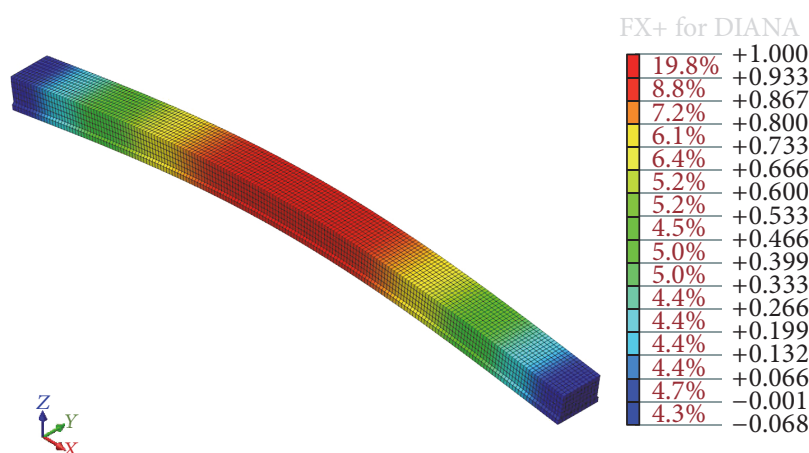

(a) Analytical 1st bending mode, $f=9.576 \mathrm{~Hz}$

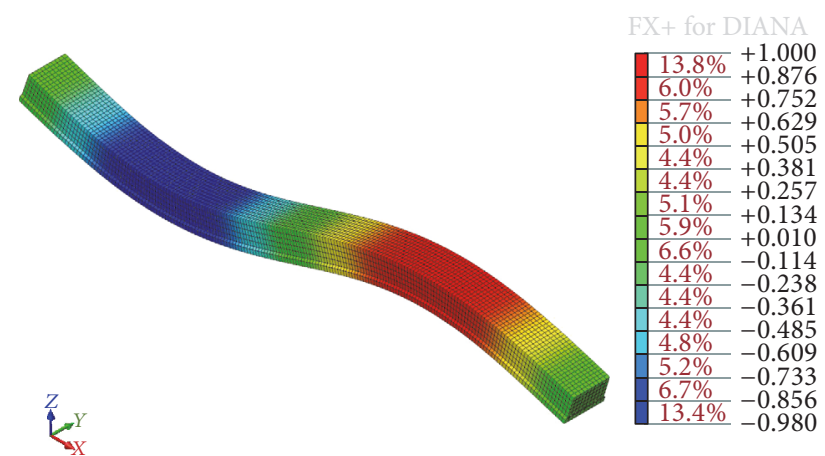

(b) Analytical 2nd bending mode $f=37.054 \mathrm{~Hz}$

Figure 23: ((a)-(b)) Analysis results of natural frequencies of girder No. 3 in May 2015.

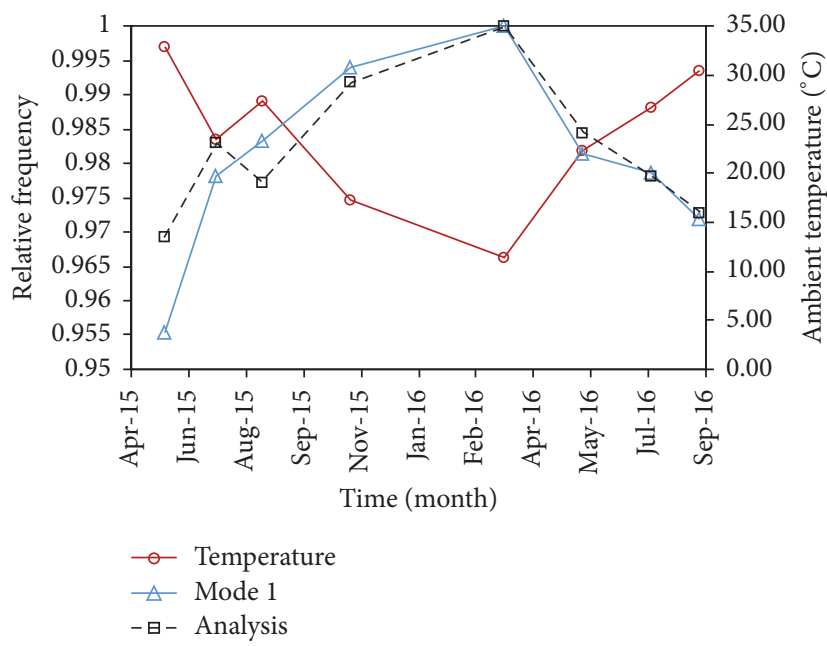

(a) The 1st bending mode (mode 1)

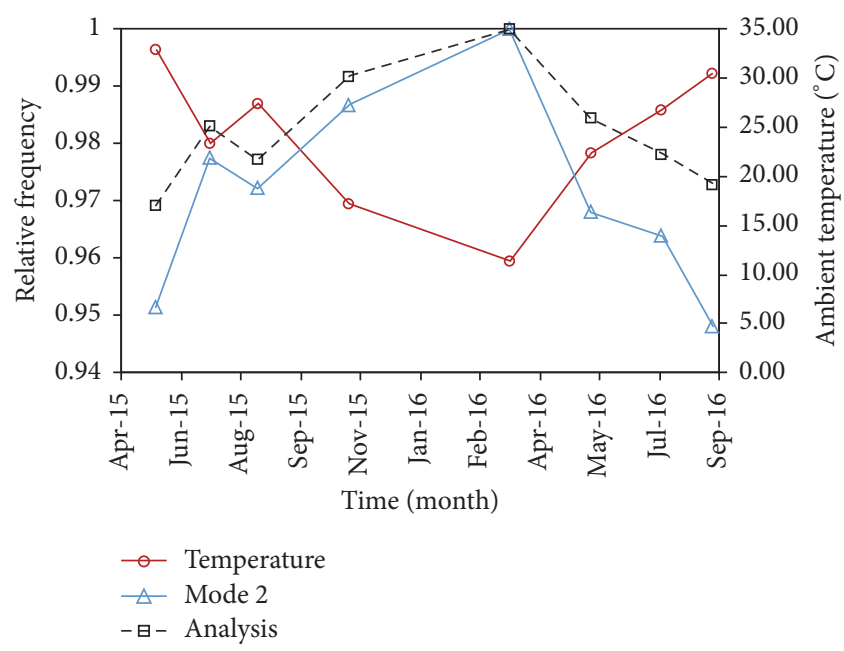

(b) The 2nd bending mode (mode 2)

FIGURE 24: ((a)-(b)) Variations in two bending modal frequencies of girder No. 3 over one and a half years.

profile might not accurately reflect the temperature of the girder. Because the main objective of the simulations was to confirm the relationship between the frequency variation and the temperature-induced change in terms of Young's modulus, the frequencies were normalized by the highest frequency in the monitoring period. Figures 24(a) and 24(b) show the variations in the relative vibrational frequencies of the two bending modes of girder No. 3 with respect to time. The figures show that the trend in the frequency variation in both the experimental and analytical results with respect to the temperature is similar. Negative relationships between the frequencies and the ambient temperature were obtained in the results: the temperature increased with the decreases in the frequencies. In addition, both the relative frequencies followed an expected trend. In other words, they increased and reached the maximum values in March 2016 when the measured ambient temperature was the lowest over the monitoring period and, subsequently, decreased until September 2016. In particular, the temperature varied by $\sim 21.55^{\circ} \mathrm{C}$ from approximately $\sim 33^{\circ} \mathrm{C}$ in May 2015 to $\sim 11.45^{\circ} \mathrm{C}$ in March 2016 (between summer and winter). This decrease led to a variation in Young's modulus of concrete, thereby increasing the analytical frequency of mode 1 by $\sim 3.1 \%$. This rate was obtained at $\sim 4.5 \%$ with respect to the measurement. The measured temperature then increased gradually by $\sim 19^{\circ} \mathrm{C}$ from a low temperature to $\sim 30.45^{\circ} \mathrm{C}$ in September 2016 (between winter and summer). Consequently, the experimental and analytical frequencies decreased by $\sim 2.8$ and $\sim 2.7 \%$, respectively. To make a consistent comparison with the other girders, this study assumed that the analytical frequencies of girders No. 1 and No. 2 varied linearly with the variation in the ambient temperature. Based on this assumption, the variation ratios of the analytical frequencies with respect to time of girders No. 1 and No. 2 were estimated and plotted in Figures 25(a), 25(b), 26(a), and 26(b), respectively. As shown in these figures, the variations in the numerical frequencies are not in agreement with the changes in the measured one. In particular, the second bending mode of girder No. 2, which is shown in Figure 26(b), exhibited a higher discrepancy compared to the other results. This noise is likely because of the ASR-induced deteriorations because many longitudinal cracks were observed on the top, bottom, 


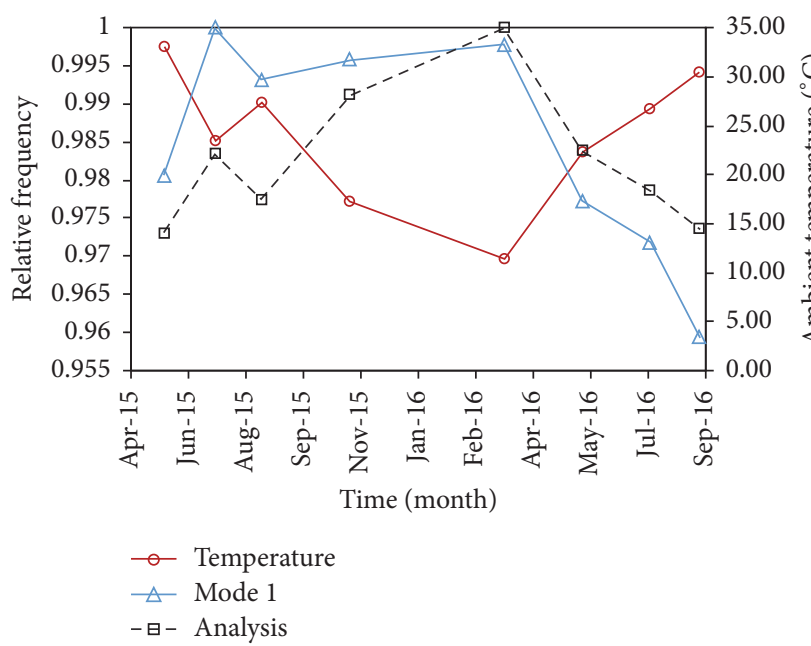

(a) The 1st bending mode (mode 1)

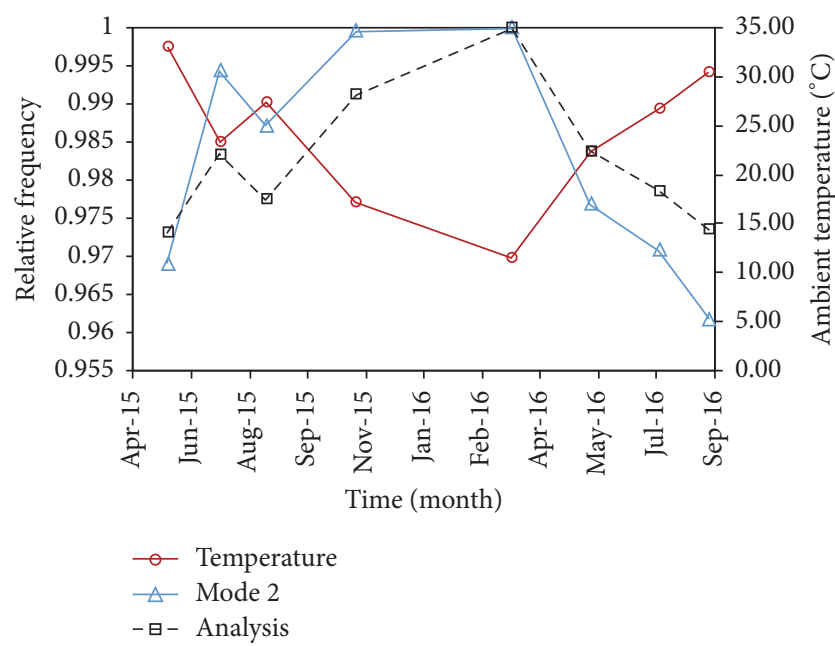

(b) The 2nd bending mode (mode 2)

Figure 25: ((a)-(b)) Variations in two bending modal frequencies of girder No. 1 over one and a half years.

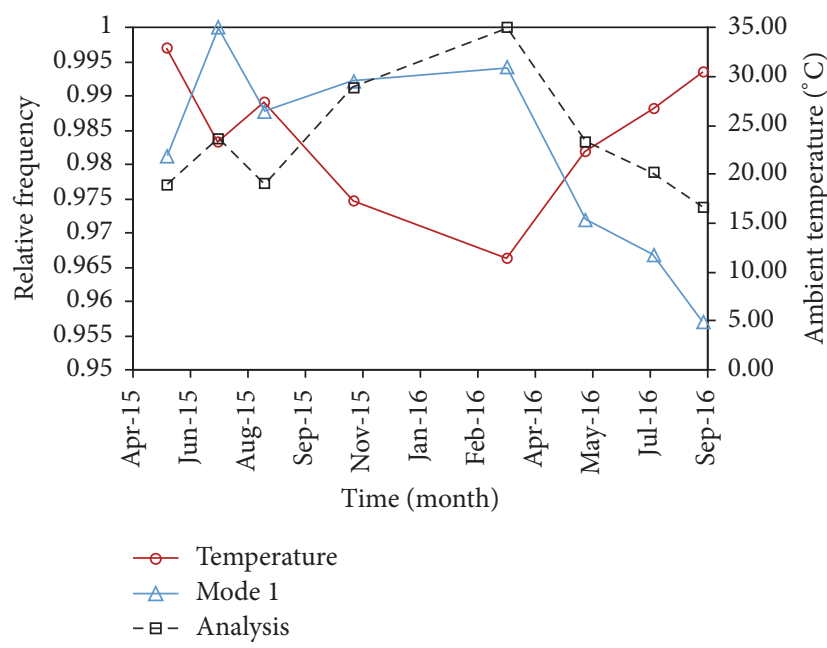

(a) The 1st bending mode (mode 1)

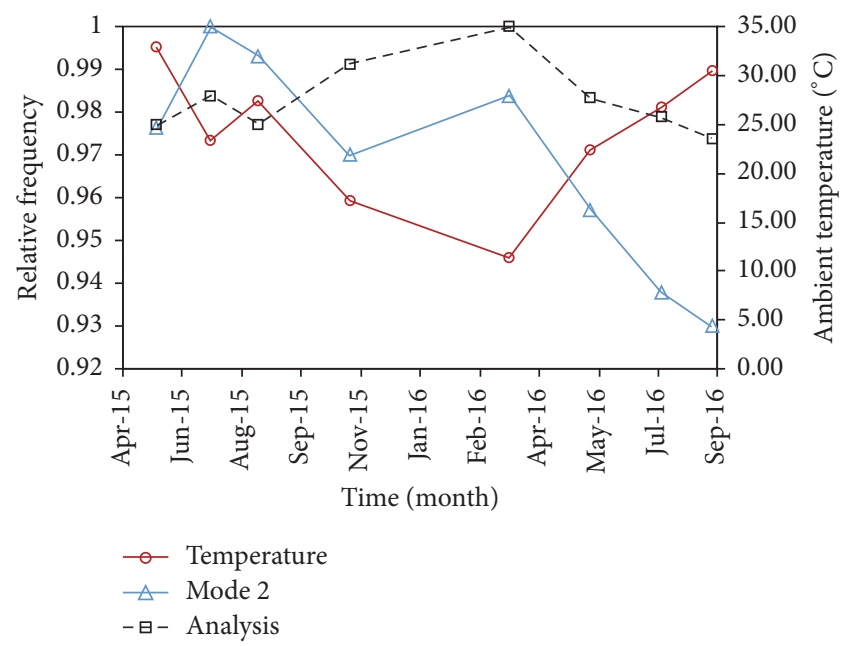

(b) The 2nd bending mode (mode 2)

FIGURE 26: ((a)-(b)) Variations in two bending modal frequencies of girder No. 2 over one and a half years.

and both side surfaces of girders No. 1 and No. 2 whereas girder No. 3 suffered only a few. In addition, it is difficult to estimate the higher order modes with precise accuracy. The results of the torsional modes were not shown because they were not identified with sufficient precision to detect the environmental effects. These obstacles were reported in other studies as well $[8,15,19]$. The results of the extensive validations show that the correlation between the variations in the natural frequencies and the temperature-induced changes in Young's modulus could be proved reasonably using the FE model developed in this study.

\section{Conclusion}

In this study, the combined effect of the changes in the environmental conditions and the ASR-induced deteriorations on the three PC girders with nonidentical mixtures was monitored for one and a half years. The main conclusions drawn from this study are as follows.

The environmental conditions strongly affected the changes in the frequencies of the vibration modes of the girders because the correlation coefficients between the variables were strong, as computed using the linear models. With regard to the relationship with the ambient temperature, the amplitude of the vibrational frequency decreased with respect to the increase in the ambient temperature. The correlation levels were comparatively moderate for girders No. 1 and No. 2 but fairly strong for girder No. 3. With regard to the effect of humidity, relatively negative relationships between the measured frequencies and humidity were obtained. The ambient humidity affected the frequencies of the bending modes of girders No. 1 and No. 2 more significantly than those of girder No. 3. This observation can be attributed to the influence of the ASR-induced cracks because water could 
be absorbed and dispersed easily in girders No. 1 and No. 2 . The results of the error analysis show that the bending modes could be estimated more accurately than the torsional mode because the error ratio of the torsional mode was higher than that of the bending modes.

The effects of the measured humidity and temperature on the changes in the damping ratio were negligible, though some outcomes illustrate that the damping ratios decreased relatively with the increase in the environmental parameters. Moreover, because the identified measurement noises were rather high, it was concluded that the damping ratios were not determined with sufficient accuracy to distinguish the environmental impacts.

A significant number of scatters can be seen in all the estimated MAC values with no notable pattern reflecting the variation in the amplitude with respect to the ambient temperature and humidity. The results proved that the ambient temperature and humidity affected the entire girder uniformly, and consequently, the effects of the environmental conditions on the MAC values were not meaningful.

The outcomes of the comparison between the three girders show that the differences in the measured frequencies of the three girders manifested clearly over time in terms of the two bending modes, whereas no significant deviation was observed for the frequencies of the torsional mode. In particular, the bending frequencies of girder No. 3 were higher than those of girders No. 1 and No. 2 at each measuring time. With regard to the damping ratio, similar observations were made. Although no significant difference in the amplitude of the torsional mode was obtained, the damping ratios of the other modes changed considerably. Within one and a half years of investigation, the damping ratio of girder No. 3 was found to be lower than that of the other girders. The analysis of the MAC values shows that there is no clear discrepancy in the magnitude of the MAC values considered in this study.

During the monitoring period, the bending modal frequencies of girder No. 3 fluctuated in the range of $\sim 3-5 \%$, which is considerable compared to those due to structural damage. Hence, the effects of the environmental conditions should be examined thoroughly when using the variation in the vibrational frequency to assess the health of structures.

Because the dynamic behaviors of the three girders were clearly observed to be different, the fly ash significantly affected the performances of the PC girders under the ASR damage.

\section{Conflicts of Interest}

The authors declare that they have no conflicts of interest.

\section{Acknowledgments}

This research was promoted by the Cross-Ministerial Strategic Innovation Promotion Program [Title: Resolution of Early-Aged Deterioration Mechanisms in Concrete Bridges and Development of Total Management System Based on Evaluation for Material and Structure Quality Performance, Kanazawa University] from the Japan Science and Technology Agency (JST). The authors wish to thank the concerned parties for their valuable collaboration, subconsultants, and support.

\section{References}

[1] O. Huth, G. Feltrin, J. Maeck, N. Kilic, and M. Motavalli, "Damage identification using modal data: experiences on a prestressed concrete bridge," Journal of Structural Engineering, vol. 131, no. 12, pp. 1898-1910, 2005.

[2] S. Hassiotis and G. D. Jeong, "Identification of stiffness reductions using natural frequencies," Journal of Engineering Mechanics, vol. 121, no. 10, pp. 1106-1113, 1995.

[3] Y. Xia, H. Hao, J. M. W. Brownjohn, and P.-Q. Xia, "Damage identification of structures with uncertain frequency and mode shape data," Earthquake Engineering \& Structural Dynamics, vol. 31, no. 5, pp. 1053-1066, 2002.

[4] Z. Y. Shi, S. S. Law, and L. M. Zhang, "Damage localization by directly using incomplete mode shapes," Journal of Engineering Mechanics, vol. 126, no. 6, pp. 656-660, 2000.

[5] A. K. Pandey, M. Biswas, and M. M. Samman, "Damage detection from changes in curvature mode shapes," Journal of Sound and Vibration, vol. 145, no. 2, pp. 321-332, 1991.

[6] A. K. Pandey and M. Biswas, "Damage detection in structures using changes in flexibility," Journal of Sound and Vibration, vol. 169, no. 1, pp. 3-17, 1994.

[7] Z. Y. Shi, S. S. Law, and L. M. Zhang, "Improved damage quantification from elemental modal strain energy change," Journal of Engineering Mechanics, vol. 128, no. 5, pp. 521-529, 2002.

[8] Y. Xia, H. Hao, G. Zanardo, and A. Deeks, "Long term vibration monitoring of an RC slab: temperature and humidity effect," Engineering Structures, vol. 28, no. 3, pp. 441-452, 2006.

[9] J. H. G. Macdonald and W. E. Daniell, "Variation of modal parameters of a cable-stayed bridge identified from ambient vibration measurements and FE modelling," Engineering Structures, vol. 27, no. 13, pp. 1916-1930, 2005.

[10] Z.-D. Xu and Z. Wu, "Simulation of the effect of temperature variation on damage detection in a long-span cable-stayed bridge," Structural Health Monitoring, vol. 6, no. 3, pp. 177-189, 2007.

[11] J. Kim, J. Park, and B. Lee, "Vibration-based damage monitoring in model plate-girder bridges under uncertain temperature conditions," Engineering Structures, vol. 29, no. 7, pp. 1354-1365, 2007.

[12] P. Cornwell, C. R. Farrar, S. W. Doebling, and H. Sohn, "Environmental variability of modal properties," Experimental Techniques, vol. 23, no. 6, pp. 45-48, 1999.

[13] B. Peeters and G. De Roeck, "One-year monitoring of the Z24bridge: environmental effects versus damage events," Earthquake Engineering \& Structural Dynamics, vol. 30, no. 2, pp.149171, 2001.

[14] M. Ha, S. Fukada, N. Arima, N. Moriyama, and T. Miyashita, "Study on vibration and structural performance of PC Girder removed due to salt damage," in Proceedings of the 14th East Asia-Pacific Conference on Structural Engineering and Construction, pp. 680-681, 2016.

[15] Y. Xia, Y.-L. Xu, Z.-L. Wei, H.-P. Zhu, and X.-Q. Zhou, "Variation of structural vibration characteristics versus nonuniform temperature distribution," Engineering Structures, vol. 33, no. 1, pp. 146-153, 2011. 
[16] S. Yamamura, M. Sakurada, K. Kobayashi, and K. Torii, "Application of concrete using fly ash to PC girder bridges," Cement \& Concrete, vol. 828, pp. 22-27, 2016.

[17] J.-N. Juang and R. S. Pappa, "An eigensystem realization algorithm for modal parameter identification and model reduction," Journal of Guidance, Control, and Dynamics, vol. 8, no. 5, pp. 620-627, 1985.

[18] The R Manuals, 2017, https://cran.r-project.org/manuals.html.

[19] P. Moser and B. Moaveni, "Environmental effects on the identified natural frequencies of the Dowling Hall Footbridge," Mechanical Systems and Signal Processing, vol. 25, no. 7, pp. 2336-2357, 2011.

[20] N. Sugiura, K. Kobayashi, S. Fukada, and K. Torii, "Diagnosis the ASR deterioration of the prestressed concrete girder by cylinder cores," in Proceedings of the JCI annual convention, Sendai, Japan, 2017.

[21] A. D. Dimarogonas, "Vibration of cracked structures: a state of the art review, Engineering Fracture Mechanics, vol. 55, no. 5, pp. 831-857, 1996.

[22] M. Rezaee and H. Fekrmandi, "A theoretical and experimental investigation on free vibration vehavior of a cantilever beam with a breathing crack," Shock and Vibration, vol. 19, no. 2, pp. 175-186, 2012.

[23] A. P. Bovsunovskii, "Numerical study of vibrations of a nonlinear mechanical system simulating a cracked body," Strength of Materials, vol. 31, no. 6, pp. 571-581, 1999.

[24] R. O. Curadelli, J. D. Riera, D. Ambrosini, and M. G. Amani, "Damage detection by means of structural damping identification," Engineering Structures, vol. 30, no. 12, pp. 3497-3504, 2008.

[25] D. J. Ewins, Modal Testing: Theory and Practice, Research Studies, New York, NY, USA, 2nd edition, 2000.

[26] "User's manual of FX+ for DIANA version 9.6. Tnodiana.com," 2016, https:/support.tnodiana.com/manuals/d96/Diana.html.

[27] V. Kodur, "Properties of concrete at elevated temperatures," ISRN Civil Engineering, vol. 2014, Article ID 468510, 15 pages, 2014.

[28] P. J. Barr, J. F. Stanton, and M. O. Eberhard, "Effects of temperature variations on precast, prestressed concrete bridge girders," Journal of Bridge Engineering, vol. 10, no. 2, pp. 186-194, 2005.

[29] W. Li, R. Wang, D. Li, and D. Fang, "A model of temperaturedependent Young's modulus for ultrahigh temperature ceramics," Physics Research International, vol. 2011, Article ID 791545, 3 pages, 2011.

[30] "EN, 1992-1-2: Design of concrete structures. Part 1-2: general rules-structural fire design. Eurocode 2, European Committee for Standardization, Brussels, Belgium," 2004.

[31] V. R. Kodur and T. Z. Harmathy, "Properties of building materials," in SFPE Handbook of Fire Protection Engineering, P. J. DiNenno, Ed., National Fire Protection Association, Quincy, MA, USA, 2008.

[32] CEB-FIP, Model Code 1993, Thomas Telford, London, UK, 1993.

[33] S. Fukada, T. M. Ha, K. Kobayashi, and K. Torii, "Influence on load carrying capacity of $\mathrm{PC}$ girder using reactive aggregate by fly ash," Proceedings of the Japan Concrete Institute, vol. 39, no. 2, pp. 355-360, 2017. 


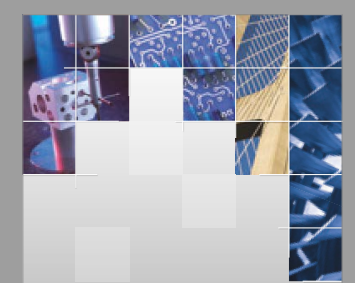

\section{Enfincering}
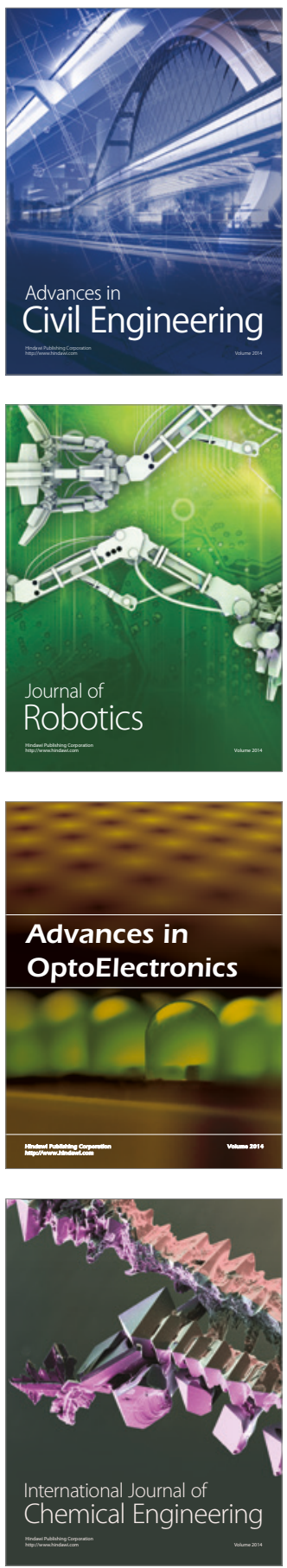

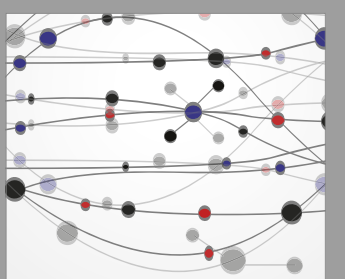

The Scientific World Journal

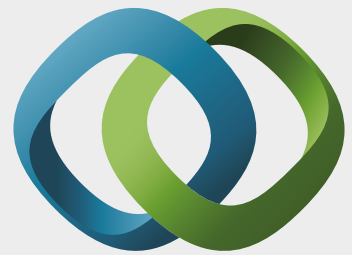

\section{Hindawi}

Submit your manuscripts at

https://www.hindawi.com
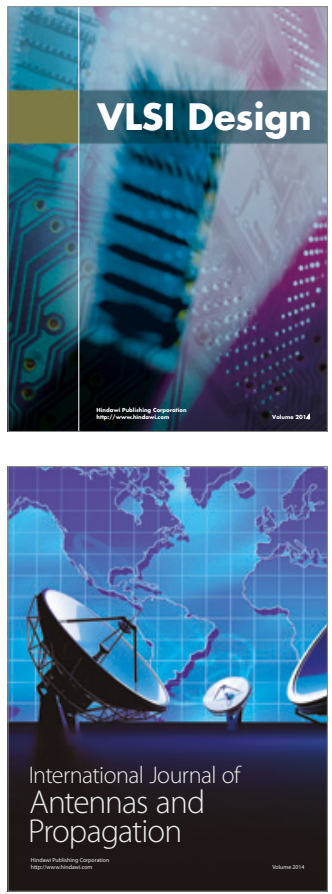

\section{Rotating}

Machinery
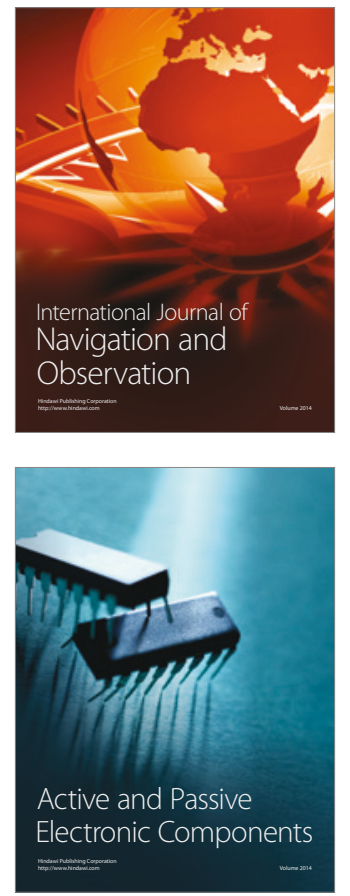
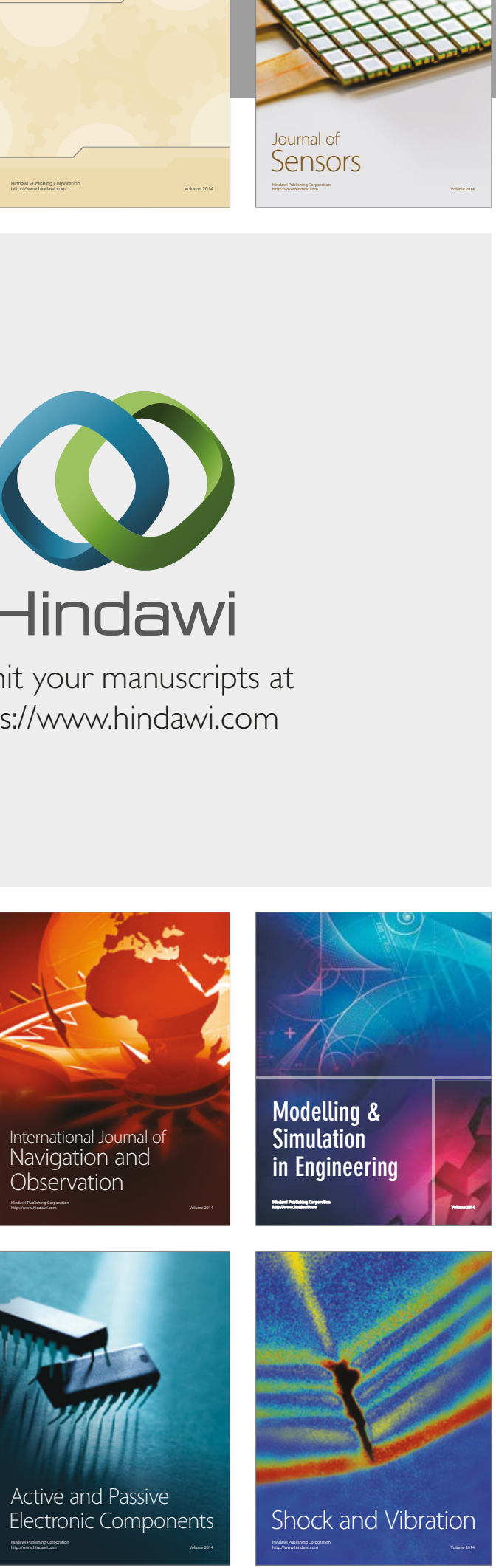
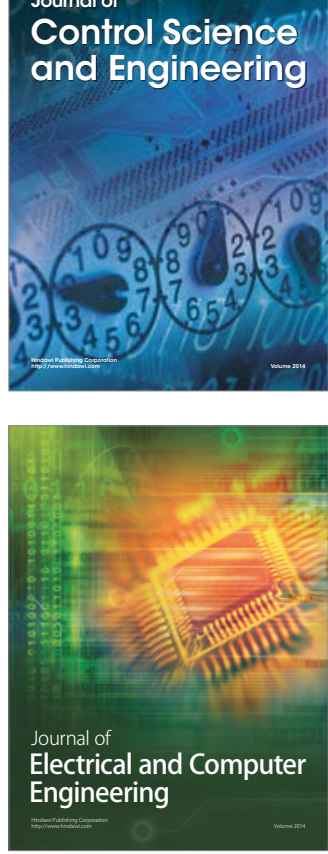

Distributed

Journal of

Control Science

and Engineering
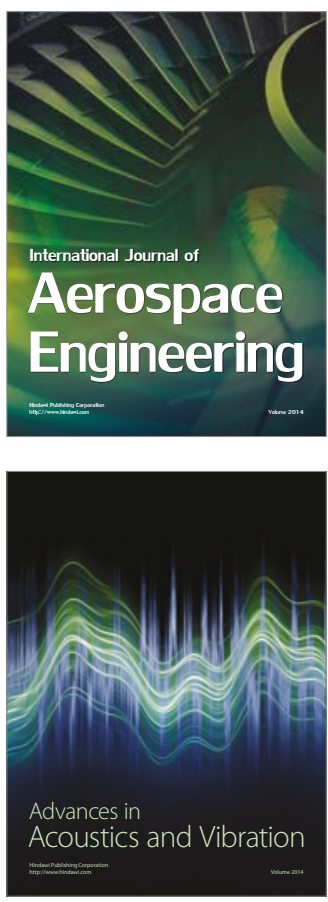

Sensor Networks 